\title{
MASSED AND DISTRIBUTED PRACTICE EFFECTS \\ ON THE AGQUISITION AND RETENTION \\ OF A NOVEL BASKETBALL SKILL
}

\begin{abstract}
DISSERTATION
Presented in Partial Fulfillment of the Requirements for the Degree Doctor of Philosophy in the Graduate School of The Ohio State University
\end{abstract}

By

Robert Norman Singer, B.S., M.S.
\[ * * * * * \]

The Ohio State University 1964

Approved by

,

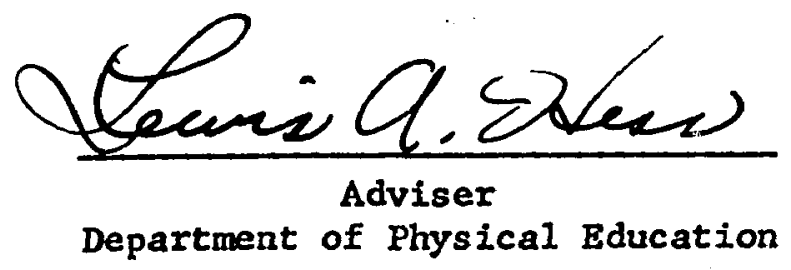




\section{ACKNOWLEDGEMENTS}

The writer wishes to express his appreciation, first of all, to Dr. D. D. Wickens of the Department of Psychology for assistance and guidance in the design and preparation of this study. For their generous assistance in the preparation of the manuscript, the author wishes to express his gratefulness to Dr. Lewis A. Hess and Dr. Bruce L. Bennett.

The advice of Dr. James C. Naylor and Dr. Donald R. Meyer of the Department of Psychology relative to the statistical treatment of the data was most helpful and useful.

Finally, the writer wishes to put in print that which he has often failed to do verbally, that is to acknowledge the understanding, patience, and assistance generated throughout the study by his wife, Maita. 
VITA

September 27, 1936

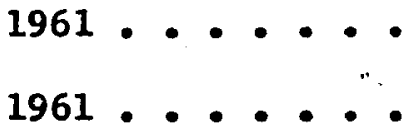

1961-1962 •.. •

1962

$1962-1963$

1963-1964 • • •
Born - Brooklyn, New York

B.S., Brooklyn College, Brooklyn, New York

Physical. Education and Biology Teacher, Erasmus High School, Brooklyn, New York

Graduate Assistant, Department of Physical Education, The Pennsylvania State University, University Park, Pennsylvania

M.S., The Pennsylvania State University, University Park, Pennsylvania

Graduate Assistant, Department of Physical Education, The Ohio State University, Columbus, Ohio

Instructor, The Ohio State University, Columbus, Ohio

PUBLICATIONS

"Future Consideration of Undergraduates: Becoming a Graduate Assistant," The Ohio High School Athlete, 23:124-125, February, 1964.

"Camping and Education,", The Physical Educator, 21:75-76, May, 1964.

FIEIDS OF STUDY

Major Field: Physical Education

Studies in Higher Education. Professor Everett J. Kircher

Studies in Psychology. Professors Delos D. Wickens and George G. Thompson. 
CONTENTS

CHAPTER

PAGE

I. INTRODUCTION TO THE FROBLEM . . . ...........

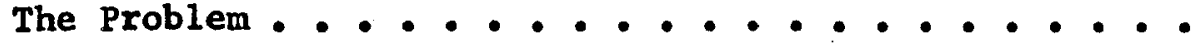

Statement of the problem . . . . . . . . . 7

Limitations of the study ............ 7

Importance of the study . . . . . . . . . . 7

Definition of Terms Used .............. 9

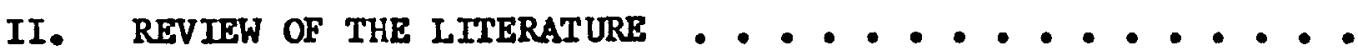

Distribution of Practice as a Function of the

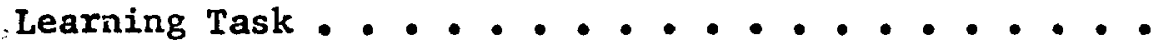

Distribution Effects as a Function of the Length

of the Rest Interval ................

Ketention Following Massed and Distributed Practice .

Reminiscence as a Function of the Material to be

Learned . . . . . . . . . . . . . . . .

Reminiscence as a Function of the Previous Degree

of Distribution of Practice .............

Reminiscence as a Function of the Length of

the Rest Interval .............. 42

Theories of Reminiscence and the Distribution Effect - 45

Summary of the review of 1iterature . . . . . 50 
III. PROCEDURES . . . . . . . . . . . . . . .

Novel Skill Learned .. .. . . . . . . . . 52

Administration of Practice . . . . . . . . 54

IV. ANALYSIS OF DATA ....................

Acquisition of the skill ...............

Retention of the skill ............... .

v. SUMMARY AND CONCLUSIONS . . . . . . . . . . . .

Summary . . . . . . . . . . . . . 76

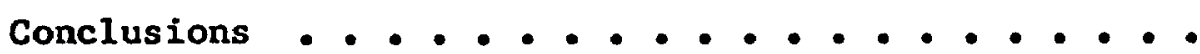




\section{LIST OF TABLES}

TABLB

PAGE

I. Analysis of Variance Test for Homogeneity of Groups - .

II. Mean Scores and Standard Deviations for Massed and Distributed Groups Each Twenty Trials During Practice.

III. Analysis of Variance of Performance During Practice . .

IV. Duncan Multiple Range Test on Ordered Means To

Determine Significance of the Differences Between

Means of Groups Every Twenty Trials During Practice • •

v. Mean Scores and Standard Deviations for Massed and

Distributed Groups Tested for Retention . . . . . .

VI. Analysis of Variance of Performance on Tests Given One

Day and One Week After the Completion of Practice...

VII. Duncan Multiple Range Test on Ordered Means to Determine Significance of the Differences Between Means of Groups Tested One Day and One Week Following the Conclusion of Practice . . . . . . . . . . .

VIII. Analysis of Variance of Performance on Tests Given At the End of Practice, After Interpolated Rest Periods, and One Month Following the Completion of Practice ... .

IX. Duncan Multiple Range Test on Ordered Means to Determine Significance of the Differences Between Means of Groups Tested at the End of Practice, After Interpolated Rest Periods, and One Month Following the Conclusion of Practice ................. 
LIST OF FIGURES

F IGURE

PAGE

1. Massed and Distributed Practice Effects on the Acquisition and Retention of a Novel Basketball

Skill As Measured by the Mean Number of Points

scored ............................

2. Kased and Distributed Practice Effects on the Acquisition and Retention of a Novel Basketball Skill As Heasured by the Total Baskets Scored . . . 
CHAPTER I

INTRODUCTION TO THE PROBLEM

Physical educators and coaches have constantly searched for the best methods whereby skill learning and performance of participants in a class activity or on a team might be improved. The distribution of time to be allotted for the learning and retaining of a specific skill has posed a serious problem, especially since there are usually many skills to be learned in a limited period.

of course, there are many factors other than time allotted to practice which are involved in the eventual acquisition of a skill. Some factors are obvious and observable, e.8., the relative difficulty of the skill, the amount and quality of instruction given by the instructor, facilities and equipment, the over-al1 coordination of the learner, his past experiences in relevant skills, and his maturity (age of readiness). Other factors are not as apparent. These might include motivation and determination, stress, and mental and physical readiness. Many of these variables are difficult to isolate, let alone control. However, it is the concern and the obligation of the educator to provide conditions as favorable as possible for the learning situation.

One aspect of learning and performance which can be controlled by the instructor is the amount and distribution of time to be designated for the acquisition of a skill. The instructor or coach is not only interested in providing a period of long enough duration for skill attainment but also to proportion the time so that it might bring the most 
desired immediate and future results. He is ultimately faced with two possibilities.

On the one hand, he could have his students consistently and continuously practice the skill to be learned without any intermittent pauses. This method has been termed "massed practice."

On the other hand, the subjects might learn the skill in shorter but more frequent practice sessions. These practice periods would be divided by rest intervals or intervals of alternate skill learning and this condition is known as "distributed practice." Is the continuous practice period more effective in skill acquisition and retention than one broken up by spaced rest periods? Is it better to practice a task with very little interruption for rest or is rest beneficial to learning and performance? What are the optimum intervals between practice periods?

Attempts to improve learning efficiency in any field of activity must consider the problem of optimal spacing of training sessions. Some instructors are in favor of teaching a skill in one session and having the students practice this skill repetitiously in the one period. Other Instructors believe in requiring the students to practice different skills for a short duration at each meeting. The actual length of time devoted to the learning of a skill under massed and distributed conditions might be the same. However, under massed corditions the practice of the skill occurs continuously in one session whereas the practice of this same skill under distributed conditions would be limited each session but practiced in a number of sessions. The relative effectiveness of concentrating all practice or 
study into one sitting as compared with dividing it into smaller units indulged in at varying intervals of time is an important problem in the study of the learning process. The problem exists throughout a wide range of activities, from academic preparation to athletics. Numerous studies have been completed in psychology on the distribution effects on learning, with the first demonstrated in 1885 by Ebbinghaus. 1 These effects have been studied under a wide range of experimental materials and methods, e.g., verbal material (mainly nonsense syllables), 2 mirror drawing, 3 aerial gunnery, 4 and maze learning. 5 In summing up the available research, Deese concludes: "For the vast majority of psychomotor skills, distributed practice is superior to massed practice. For many verbal tasks, this is also true." 6

The problem of spaced practice is concerned primarily with the acquisition of learning material, but the related problem of retention of what has been acquired has also been the object of experimental study.

${ }^{1}$ John A. McGeoch and Arthur L. Irion, The Psychology of thiman Learning (New York: Van Rees Press, 1952), p. 138.

${ }^{2}$ Car1 I. Hovland, "Bxperimental studies in Rote-Learning Theory. III. Distribution of Practice With Varying Speeds of Syllable Presentation," Journal of Experimental Psychology, 23:172-190, August, 1938.

${ }^{3}$ Irving Lorge, "Influence of Regularly Interpolated Time Intervals Upon Subsequent Learning," Teachers College Contributions to Education, No. $438,1930$.

${ }^{4}$ Meredith P. Crawford et al. (ed), "Psychological Research on Operational Training in the Continental Air Forces," Army Air Forces Aviation Psychology Program Research Reports, 16: 260-262, 1947.

5homas W. Cook, "Distribution of Practice and Size of Maze Pattern," British Journal of Psychology, 27:303-312, 1936-1937.

${ }^{6}$ James Deese, The Psychology of Learning (New York: McGraw-Hill Book Company, Inc., 1958), p. 191. 
Some studies show a continual drop in retention (forgetting).7 Contrarily, a number of studies have deamiscrated that the retention curve does not drop rapldly following learning but instead continues to rise. 8 This improvement in the recall of a task after periods of rest has been termed reminiscence. 9 It is the cpposite of forgetting, which is poorer recall following periods of no practice.

If reminiscence can be shown to be a factor in athletic performance, it should be the concern of the physical educator, for not only is he interested in immediate skill acquisition but also in later skill performance. Possibly, some practice comditions y be more advantageous for reminiscence than others; they permanence. Unfortunately, very little work be found in the experimental 1iterature relating to the distribution of prectice effects on the learning and retaining of gross motor skills; or more specifically, athletic skills.

Nevertheless, leading physical edveators $10,11,12$ are in general agreement in their opinion that short, frequeat performances are more

${ }^{7}$ Clyde E. Noble, "Absence of Reminiscence in the Serial Rote Learning of Adjectives," Journal of Experimental Psychology, 40:622-631, October, 1950.

8Lwis B. Ward, "Reminiscence and Rote Learning," Psychological Yoinographs, $49: 1-64,1937$.

9Philip B. Ballard, "Oblivisence and Reminiscence," British Journal of Psychology Monograph Supplearents, No. 2, 1913.

10 Jackson R. Sharman, The Teching of Fursical Bducation (New York: A.S, Barnes and Company, 1936), PP. 132-133.

${ }^{11_{\text {Delbert }}}$ Oberteuffer, Physical Bducation (Nev York: Harper \& Row, 1962), p. 275.

${ }^{12}$ Charles Bucher, Foundations of Fursical Education (St. Louis: The C.V. Mos by Company, 1960), p. 305. 
favorable and profitable to learning (hence performance) than long sessions crowded into a brief span of tine. Two imestigations 13,14 using physical education activities have demontrated reminiscence. However, after summarizing the research in the area, whr concludes:

Although the sum of the physical education findings agree with those in psychology, the evidence is far too scanty to uphold the assumption that distributed practice will result in more cffective learning than mased practice. 15

Rarick also states:

Psychologists have studied extensively the effect of duration and distribution of practice sessions upon verbal and fine motor learning, but the applicability of these generalizations to the learning of gross motor skills needs further study. 16

One of the major reasons for the lack of research in physical education on the topic of massed versus distributed practice is probably the difficulty experimenters have in controlling the many variables involved in the learning of athletic skills. Individuals vary from day to day, in general health, fatigue, mood, motivation, and in interest. These elements cannot be controlled expericentally, and a passing state of fatigue or mood at the tive of the learning or testing

13 Margaret G. Fox and Vera P. Young, Maffect of Reminiscence on Learning Selected Badminton Skills," The Research Quarterly, 33:386-394, October, 1962.

${ }^{14}$ Bonnie J. Purdy and Ailene Lockhart, WRetention and Relearning of Gross Motor Skills After Long Periods of No Practice," The Research Quarterly, 33:265-272, May, 1962 .

${ }^{15}$ Dorothy R. Mohr; "The Contributions of Physical Activity to Skill Learning," The Research Quarterly, 31:321-351, Hay, 1960, Part II.

${ }^{16}$ G. Lawrence Rarick, "Physical Education," Encyclopedis of Educational Research, Chester W. Harris, editor (Nev York: The Macmillan Company, 1960), P. 984. 
w111 entirely alter the ultimate results.

Secondly, there is much more difficulty in arranging the experimental design for a gross motor study as compared to a study investigating fine motor skills and verbal learning. The time element and study conditions are important considerations, and both time and experimental conditions are more easily controlled in fine motor skill and verbal learning studies.

Finally, physical educators and coaches have displayed a serious lack of interest in the area of motor learning. Much of the experimental research currently being undertaken by physical educators has been concentrated in the area of physiology.

Therefore, most theories on the difference between continuous and interval practice as related to gross motor skill acquisition have been inferred from the studies on verbal and fine motor skill learning which minimize the possibility of this source of experimental complication. As was noted before, these studies generally show that the introduction of time intervals between practice periods yields more rapid learning than does continuous practice. Because of the hazard of applying inferences from one experimental area to an apparently related one, the present study was designed to retest the long-established superiority of distributed practice over massed practice.

Very few studies which isolated a gross motor athletic skil1 and tested its acquisition and retention under actual massed and spaced practice conditions are to be found in the literature. A preliminary experiment studying the effects of massed versus distributed practice on the learning of a novel basketball skill was directed earlier by the writer. 
The results of the study, although lmmediately favoring the distributedpractice group, eventually showed the massed-practice group to have superior performance. These results suggest that further study is necessary in the area of practice effects on gross motor skill learning and that this investigation should be more thorough and systematic, hence, this project.

\section{THB PROBLEM}

Statement of the problem. The purpose of this study was to determine the effects of massed and distributed practice on the learning and retention of a novel basketball skill, bouncing the ball off the floor and into the basket. Hore specifically, the study will attempt to

1) Compare performance during practice under massed and two different distributed practice conditions.

2) Compare differences between the three types of conditions at the completion of practice, one day later, one week later, and one month 1ater.

3) Determine any effects of reminiscence.

Limitations of the study. The study was limited to $120 \mathrm{male}$ freshman students who were enrolled in the required physical education program at The Ohio State University during the spring and autumn quarters, 1963. These students were volunteers from this investigator's classes.

Importance of the study. The major cause for the undertaking of this study is to determine the desirability of one method over the 
other (massed or distributed) in terms of better immediate and future results in skill performance. If there is found to be a significant difference in performance resulting from the dissimilarity of practice conditions, it is hoped that these results might be of assistance in the planning and teaching of physical education classes and the coaching of athletic teams.

Also, the current conclusive belief in the more favorable effects of distributed practice over massed practice might be substantiated or questioned according to the results obtained in this study. As has been noted earlier in the chapter, psychomotor and verbal skill learning have usually been favored under interval practice condi:ions. Evidence in physical education is too sparse thus far to make conclusions as to the effectiveness of one practice method over the other.

Finally, at the theoretical level, this study is concerned with the Hullian 17 constructs (later formalized and extended by Kimble18) of reactive inhibition $\left(I_{R}\right)$ and conditioned inhibition $\left(S I_{R}\right)$ as an explanation of the practice effects which have been discussed in this chapter. Both $I_{R}$ and $S I_{R}$ are postulated as being two inhibitory processes caused by the mere repetition. of a task; both are presumed to depress performance.

Reactive inhibition is temporary by nature and dissipates with time while conditioned inhibition is permanent. $I_{R}$ is regarded as a negative drive state which is essentially a need to cease action and in

17Clark L. Hull, Pxinciples of Behavior (New York: D. AppletonCentury Company, 1943), pP. 276-287, 391-392.

${ }^{18}$ Gregory A. Kimble, "An Experimental Test of a Two-Factor Theory of Inhibition," Journal of Experimental Psychology, 39:15-23, February, 1949. 
this sense at least, it is closely related to what is popularly called fatigue. The effect of $I_{R}$ on the individual is to reduce the work-output level of the individual and to obscure the actual level of the strength of the habit as indicated by the performance level.

Application of the theory to the practice conditions used in this study would explain why a subject who learns under relatively massed practice exhibits a depressed performance but after a rest interval will supposedly improve as the $I_{R}$ dissipates; thus resulting in the phenomenon termed reminiscence. The concept of $I_{R}$ and $S^{I_{R}}$ will be discussed in greater depth in Chapter II, but the above should suffice as an introduction to the theory.

The reaction inhibition theory is one of the most appealing and widely used theoretical notions in experimental studies dealing with practice effects on learning and performance. Because one of the leading psychology learning theorists, McGeoch, 19 has stated that of all the hypotheses at present, the reaction inhibition theory and the differential forgetting theory offer the best-supported explanatory significance, it was decided to observe whether the results of this study, using an athletic skill, would conform to the reaction inhibition theory.

\section{DEFINITION OF TERMS USED}

Distributed practice. The practicing of a skill with constant rest intervals regularly interspersed after each constant unit of practice. 20 Distributed practice is also referred to as spaced or Interval practice.

${ }^{19}$ McGeoch and Irion, op. c1t., p. 189.

${ }^{20}$ Lorge, 오. cit., p. 2 . 
Learning. A change in performance which occurs, under the concifions of practice. 21

Massed practice. The condition in learning in which each trial is Immediately followed by another trial and there are no intervening rest periods between the successive trials. 22 Massed practice can also be referred to as repetitious or continual practice.

Motor skill. The effective performance of motor movement patterns in terms of the results achieved. 23

Novel skill. A unique skill that has not been previously attempted by the subject. In this study, the novel skill is bouncing the basketball off the gymnasium floor and into the basket.

Performance. An act or movement which demonstrates or indicates how much learning has taken place. 24

Reminiscence. An actual improvement instead of a decrement on a test of performance of a partially learned skill after a period of rest in which no practice could have occurred. 25

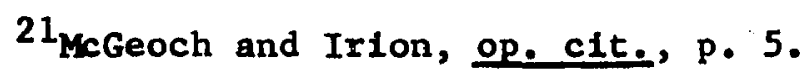

${ }^{22}$ Lorge, 으. cit., p. 1

23 Joanne Black, "An Experimental Study of the Learning of Motor Skili" (unpublished Master's thesis, The Pennsylvania State University, 1949), p. 3.

24Brnest R. Hilgard, Theories of Learning (New York: AppletonCentury-Crofts, Inc., 1956), Pp. 4-5.

25 Deese, op. cit., P. 192. 
CHAPTER II

REVIEW OF THE LITERATURE

Comparison of distributed and massed practice has both practical and theoretical significance. Practical interest centers in the determination of the circumstances leading to more efficient learning, while theories provide hypotheses which offer to explain and predict results under various practice conditions. Many studies and theories may be found in the experimental literature related to the problem of massed versus distributed practice. Therefore, for the sake of conciseness and facilitation of review, this chapter will be partitioned under the following titles: (1) Distribution of Practice as a Function of the Learning Task; (2) Distribution Effects as a Function of the Rest Interval; (3) Retention Following Massed and Distributed Practice; (4) Reminiscence as a Function of the Material to be Learned;

(5) Reminiscence as a Function of the Previous Degree of Distribution of Practice; (6) Reminiscence as a Function of the Length of the Rest Interval; and (7) Theories of Reminiscence and the Distribution Effect.

DISTRIBUTION OF PRACTICE AS A FUNCTION OF THE LEARNING TASK

The beneficial effects of distributing practice as contrasted to massing it have been demonstrated in many studies concerned with the problem. This section of the review of literature will present investigations representing the wide assortment of experimental materials used thus far to study the effects of massed and distributed 
practice. The materials include prose, nonsense syllables, inverted alphabet writing, digits, symbols, concepts, mirror drawing, mazes, reaction time, pursuit rotors, aerial gunnery, piano playing, typing, and various athletic skills.

In an early investigation, Iyon used himself as a subject and studied passages of prose, poetry, nonsense syllables, and digits under continuous and once-per-day conditions. 1 He found the distributed method to be far superior to the continuous method in the learning of nonsense syllables and digits. The learning of poetry and prose was equally efficient under both practice conditions. Patten had sixteen subjects learn nonsense syllables every day for sixteen days. ${ }^{2}$ Each subject learned half of the nonsense syllables under massed conditions and half the syllables under spaced practice whereby a two minute rest was introduced following each trial. He concluded that the distributed practice group learned in significantly fewer trials and also recalled more after a ten minute interval.

Hovland also investigated the learning of nonsense syllables under massed and interval conditions. ${ }^{3}$ Thirty-two subjects were required to master twelve-unit lists of nonsense syllables by the anticipation method.

${ }^{1}$ Darwin 0. Lyon, "The Relation of Length of Material to Time Taken For Learning and the Optimum Distribution of Time," Journal of Educational Psychology, 5:85-91, 1914 .

${ }^{2}$ Everett F. Patten, "The Influence of Distribution of Repetitions on Certain Rote Learning Phenomena," Journal of Psychology, 5:359-374, 1938.

${ }^{3}$ Carl I. Hovland, "Experimental studies in Rote-Learning Theory. III. Distribution of Practice With Varying speeds of Syllable Presentation," Journal of Experimental Psychology, 23:172-190, August, 1938. 
There was a six second pause between trials designated for the massed practice group and two minute or six minute rests for the distributed practice groups. Using a criterion of one perfect recitation of the Iist, Hovland discovered that seventy-two per cent of the subjects learned better by the distributed method.

Kientzle studied inverted alphabet learning with a large sampling of students who were divided into four groups and were allowed twenty one-minute trials. Group A had twenty massed trials, B had fifteen massed and five distributed, $C$ received twenty distributed trials, and $D$ had fifteen distributed plus five massed trials. All distributed trials were spaced with sixty second rests. Distributed practice (Group C) was found to be superior to massed practice (Group A). When Group B changed from massed to interval practice there was an immediate increase In performance while Group D decreased their output when they were altered from a distributed schedule to a continual one. 4

Robinson investigated memorization of lists of ten three-place digits. In one of his experiments, one group of subjects was given twelve presentations of the lists at one setting and another group was given six presentations at one time and six more twenty-four hours later. The subjects had to recall as many digits as possible. Distributed practice resulted in more correct digits recalled and less time for recalling them while the massed practice group recalled more of the digits. Therefore, Robinson concluded that retention of numbers following massed

${ }^{4}$ Mary J. Kientzle, "Ability Patterns Under Distributed Practice," Journal of Experimental Psychology, 39:532-537, August, 1949. 
and distributed practice appeared to be dependent upon the measures of proficiency employed. 5

Using three measures of symbolic learning, Garrett found the easier tests (code learning and symbolic digit) to be favored more under distributed practice conditions while the difficult test (artificial language) proved to be more efficientiy learned under massed practice. 6 Underwood, in studying verbal concept learning, had two groups practice with four second and thirty second rest periods between trials under three degrees of intralist similarity. Both groups received a constant number of learning trials and were tested after twenty-four hours. Learning occurred as a consequence of massed and distributed practice but there was no significant difference between groups. ${ }^{7}$ Oseas and Underwood were also interested in concept learning, and they used three geometric forms, triangles, squares, and circles. Four groups of eighteen subjects practiced with one of four different trials rests: six, fifteen, thirty, or sixty seconds. A retention test twenty-four hours after the completion of practice demonstrated that all groups performed better than the six second rest group. Differences were small but consistent and the writers concluded that geometric concept learning was favored to a greater degree under more widely spaced practice trials. 8

5Edward S. Robinson, "The Relative Efficiencies of Distributed and Concentrated Study in Memorizing," Journal of Experimental Psychology, 4:327-343, October, 1921.

6 Henry E. Garrett, "Variability in Learning Under Massed and Spaced Practice," Journal of Experimental Psychology, 26:547-567, June, 1940.

${ }^{7}$ Benton J. Underwood, "Studies of Distributed Practice: XV. Verbal Concept Learning as a Function of Intralist Interference," Journal of Experimental Psychology, 54:33-40, July, 1957.

8Leonard Oseas and Benton J. Underwood, "Studies of Distributed Practice: V. Learning and Retention of Concepts," Journal of Experimental Psychology, 43:143-148, February, 1952. 
Mirror drawing has been studied by some investigators under massed and spaced conditions. Snoddy, using a stabilimeter for mirror tracing purposes, found distributed practice to yield more superior results than massed practice. 9 Gentry was concerned with mirror reading and code substitution. Five groups in his study had twenty one-minute practice trials under varying massed and distributed situations. Output was best under distributed practice and least under massed practice, and a change from massed to distributed practice resulted in an improvement in performance.10 Similarly, Tsao also found early massing and later distributing to be most effective of the four practice conditions used by four groups of air force men learning mirror drawing. 11

Various types of mazes have been utilized by experimenters in order to observe the learning process. In an early study, Carr divided twenty subjects into two groups and gave them twenty trials to learn a pencil maze. One group received ten consecutive trials the first day, then one per day for ten days. The other group had one trial for ten days, then ten consecutive trials on the eleventh day. Carr found distribution of early trials to be more effective than in the later stages but overall, both groups performed similarly. 12

${ }^{9}$ George S. Snoddy, "Learning and Stability," The Journal of Applied Psychology, 10:1-36, 1926.

${ }^{10}$ John R. Gentry, "Immediate Effects of Interpolated Rest Periods on Learning Performance," Teachers College Contributions to Education, No. $799,1940$.

${ }^{11}$ J.C. Tsao, "Shifting of Distribution of Practice in Mirror Drawing," Journal of Experimental Psychology, 40:639-642, October, 1950.

12 Harvey Carr, "Distribution of Effort," Psychological Bulletin, $16: 26-28$, January, 1919 . 
Cook practiced 224 rats on a $T$ maze under seven different temporal conditions. His results showed the massed practice to be superior if the maze was relatively simple and the distributed effort better if the maze was decidedly difficult. The maze with a moderate degree of difficulty was not learned more quickly by any one method of distribution. 13 Using U-type high-relief finger mazes, Cook had six. groups of human subjects (six to eight in a group) learn the different mazes blindfolded. The massed practice group received twenty trials in one sitting while the distributed practice group had one trial on 'each of twenty succeeding days. He found advantages for both massed and distributed practice, depending upon the types of measurements employed and the lengths of the maze patterns in question. Distributed practice resulted in superiority of total time, in the larger maze patterns, and in the later trials. The massed practice group had less total errors, did better in early trials, and in small mazes. 14

Pechstein tested rats and humans on a difficult maze and concluded that difficult motor problems were best learned under massed conditions of practice. 15 Using varried nonsense type mazes, Cook had human subjects learn the mazes under alternating massed and distributed conditions. The massed practice group was allowed twenty second rests between trials and the distributed practice group had a one day interval between trials. He found that the massed practice group performed much better

${ }^{13}$ Sidney A. Cook, "The Effects of Various Temporal Arrangements of Practice on the Mastery of an Animal Maze of Moderate Complexity," Archives of Psychology, No. 98, April, 1928.

14 Thonas W. Cook, "Distribution of Practice and Size of Maze Pattern," British Journal of Psychology, 27:303-312, January, 1937.

${ }^{15}$ L.A. Pechstein, "Massed Versus Distributed Effort in Learning," The Journal of Educational Psychology, 12:92-97, February, 1921 . 
throughout learning, both in errors and trials to.criterion. 16

Eriksen had two groups practice on learning a multiple U-stylus maze and another two groups undertake the solution of a puzzle box. The massed practice group (practice at one sitting) did significantly better with the puzzle box while the distributed practice group (two trials per day every other day) benefited more in the maze situation. Eriksen concluded that learning problems which offer the possibility of greater initial variability of attack (the puzzle box) should benefit more from continual practice. He also suggested on these grounds that massed practice is more desirable at the beginning of learning while interval practice would aid the process of fixation toward the end. 17 Cook also studied the effects of massed and distributed practice with a puzzle which he felt offered a suitable degree of novelty and difficulty. Ten subjects were placed in two groups and were presented with twenty trials. His obtained results were similar to those of Eriksen: the massed practice group performed better early but the superiority decreased in the middle and end, where the distributed group excelled. 13

Riopelle studied the learning of responding to rapidly changing stimulus patterns (Vector Complex Reaction Time) with two groups of college students. One group received forty trials in one day whereas

16 Thomas W. Cook, "Factors in Massed and Distributed Practice," Journal of Experimental Psychology, 34:325-334, September, 1944.

${ }^{17}$ Stanford C. Eriksen, "Variability of Attack in Massed and Distributed Practice," Journal of Experimental Psychology, 31:339-345, November, 1942.

${ }^{18}$ Thomas W. Cook, "Massed and Distributed Practice in Puzzle Solving," The Psychological Review, 41:330-355, July, 1934. 
the other group had four trials per day for ten days. Performance increased for both groups but the distributed practice group always did better. Contrary to the previously mentioned studies of Cook and Eriksen, however, Riopelle found the distributed practice to offer the greatest gains early in training. 19

Montgomery constructed two experiments utilizing six perceptual motor paired associated tasks to be learned on the Duncan-Underwood Star Discrimeter. This apparatus tests steadiness while learning. Massed and distributed practice groups were given thirty-six trials and little difference in performance was found between them in Experiment $I$. However, in Experiment II, the distributed practice yielded higher performance than the massed practice. 20

Although many studies dealing with massed and spaced practice have been undertaken using pursuit rotor apparatus, only two will be reviewed here. In pursuit rotor learning, the subject attempts to hold the stylus on target as consistently and continuously as posible as the target moves in an unpredictable manner. Ammons had two groups of ten subjects take thirty-six practice trials on the pursuit rotor. The massed practice group was not allowed any rest between trials while the distributed practice group paused five minutes between, each trial. Distributed practice was favored under the various performance achievement criteria used by the experimenter. 21

${ }^{19}$ Arthur J. Riopelle, "Psychomotor Performance and Distribution of Practice," Journal of Experimental Psychology, 40:390-393, June, 1950.

${ }^{20}$ Victor E. Montgomery, "Transfer of Training in Motor Learning as a Function of Distribution of Practice," Journal of Experimental Psychology, 46:440-445, December, 1953. Pursuit "Hits"," Journal of Experimental Psychology, 41:17-22, January, 1951. 
Travis, using the Koerth pursuit rotor, utilized the services of only four subjects who, every other day, alternated under massed and distributed practice conditions. He found distributed practice (two minutes of work and one minute of rest repeated six times) to result in a consistent rise in the learning curve. The massed practice (twelve continuous minutes of work) resulted in a progressive decrease in efficiency. 22

Although most of the experimental work mentioned thus far in this chapter has utilized unrealistic learning materials and situations, the effects of the relative distribution of practice have been studied with more acceptable and natural physical skills. Crawford and others studied training missions of 221 students and found that ammunition distributed over many training missions resulted in a much greater percentage of target hits than if all the ammunition was fired in one session. However, the authors state that the study has veaknesses and is not an authentic distributed practice experiment. They feel that the results are more suggestive than conclusive. 23

In an early investigation, Pyle studied the acquisition of typing skills under massed and distributed practice conditions. Ten subjects in one group received ten half-hour periods of practice a day with a half-hour rest period between sessions for nine successive days. In the other group, ten subjects practiced for two half-hour periods a day for

${ }^{22}$ Roland C. Travis, "Practice and Rest Periods in Motor Learning," Journal of Psychology, 3:183-189, 1937.

${ }^{23}$ Meredith P. Crawford et al., "Psychological Research on Operational Training in the Continental Air Forces," Army Air Forces Aviation Psychology Program Research Reports, No. 16, $194 \overline{7 .}$ 
forty-five days. The number of words typed in the ninety practice sessions were counted, and although the massed practice group did better initially, the distributed practice group proved to be twenty-five per cent faster throughout the experiment. 24

Rubin-Rabson studied the effects of massed and distributed practice on the memorization of piano music. The three subjects in each of her three groups were allowed thirty trials. Group A practiced all their trials in one day, Group $B$ had one hour breaks between every five trials, and Group $C$ were permitted twenty-four hour rest periods after every five trials. A criterion test of one smooth memorized performance showed the distributed practice groups to perform better, although not significantly so. 25

Griffith had one group of basketball players continuously shoot a basketball for an hour while another group shot three minutes and relaxed two for an hour. The next day the procedures were reversed. Both groups shot about an equal amount of time; but when shooting with frequent rest periods the men averaged fifteen per cent more baskets than when shooting steadily. 26

Lashley investigated the acquisition of skill in archery, using twenty-six subjects who were divided into five groups. Each group shot

24W.H. Pyle, "Concentrated Versus Distributed Practice," The Journal of Educational. Psychology, 5:247-259, May, 1914.

${ }^{25}$ Grace Rubin-Rabson; "Studies in the Psychology of Memorizing of Piano Music: II. A Comparison of Massed and Distributed Practice," Journal of Educational Psychology, 31:270-284, April, 1940.

${ }^{26}$ Coleman R. Griffith, Psychology of Coaching (New York: Charles Scribner's Sons, 1932), P. 33 . 
either five, twelve, twenty, forty, or sixty arrows every day until they all had made three-hundred and sixty attempts. During the first one-hundred and eighty attempts, little difference was found; but an analysis of the later attempts showed a greater proficiency for the groups who shot under more distributed conditions. 27

Using billiard shooting as the skill to be learned, Harmon and Miller divided women subjects into four groups. After nine practice periods, it was demonstrated that the most desirable practice conditions for the acquisition of the skill was early massing and later distributing. 28

In summary, of the studies presented and reviewed in this part of the survey of literature, eighteen demonstrated superior performance with distributed practice, five fared better under massed practice, and six studies resulted in no appreciable differences due to the effects of the practice conditions. Three studies favored early massing and later distributing, one showed no difference early in practice as a result of practice conditions but demonstrated better later performance under distributed practice, while a fifth investigation favored early distribution of practice.

${ }^{27}$ K.S. Lashley, "The Acquisition of Skill in Archery," Papers From The Department of Marine Biology of the Carnegie Institute of Washington, 7:105-128, 1915 .

${ }^{28}$ John M. Harmon and Arthur G. Miller, "Time Patterns in Motor Learning," The Research Quarterly, 21:182-187, October, 1950. 


\section{DISTRIBUTION EFFECTS AS A FUNCTION OF THE LENGTH OF THE REST INTERVAL}

Since the majority of studies demonstrate a superiority of performance with subjects who practice under distributed conditions, it is important to determine the optimal period of rest between trials. In each of the studies presented here, the length of the rest periods were varied while the total amount of practice was equal between experimental groups.

Wright and Taylor studied the effects of varying the length of the rest interval upon the learning of nonsense syllables. Five groups of sixteen subjects had a total practice period of fifty-two minutes, with rest intervals of eight minutes, three and a half minutes, two minutes, one and one quarter minutes, or no minutes. The four distributed practice groups were superior to the continuous practice group in achievement in meeting the criterion of two successive perfect trials. However, no difference in performance was found under the varying rest intervals. 29

Pyle found a twenty-four hour interval between trials at code substitution better than either massed practice or trials on alternate days. There were only two subjects in each group. 30 Austin had subjects learn logical reading assignments and then recall as much as possible. The groups practiced from five repetitions in one day to one repetition

${ }^{29}$ Susan T. H. Wright and Donald W. Taylor, "Distributed Practice in Verbal Learning and the Maturation Hypothesis," Journal of Experimental Psychology, 39:52.7-531, August, 1949 .

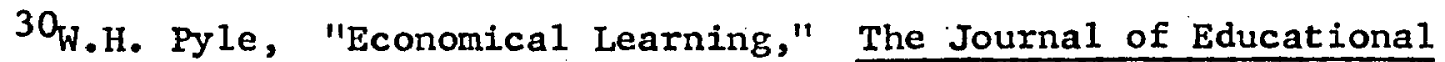
Psychology, 4:148-158, January, 1913.. 
every fifth day. A11 groups performed similarly when tested for immediate recall, while the groups that practiced once each day and once on alternate days did best on later retention tests. 31

Cummins designed four experiments in an attempt to study the learning of new words and subject matter with elementary school students. In general, he found that it is preferable to avoid long practice periods and very short intervals and that a reducing learning schedule is more profitable than one in which practice periods and rest intervals are evenly distributed. 32

Using upside down alphabet writing, Kientzle gave her experimental groups one minute trials with rest periods varying from zero seconds to seven days. Distributed practice was more beneficial than massed. In general, the longer the rest period provided the greater gain in performance but within limits, as the seven-day rest was not better than the forty-five second pause. 33 Kimble also employed inverted alphabet writing as a means of studying the effects of distributing practice. Five groups obtained twenty-one thirty second trials, with rest pauses varying at zero, five, ten, fifteen, and thirty seconds between trials for each group. Kimble found that the greater the spacing of trials the more efficient the learning. 34

${ }^{31}$ Sarah D. Austin, "A Study in Logical Memory," The American Journal of Psychology, 32:370-403, July, 1921 .

${ }^{32}$ Robert A. Cummins, "Improvement and the Distribution of Practice," Teachers College Contributions to Education, No. 97, 1919.

33 Lary J. Kientzle, "Properties of Learning Curves Under Varied Distributions of Practice," Journal of Experimental Psychology, 36:187-211, June, 1946.

${ }^{34}$ Gregory A. Kimble, "Performance and Reminiscence in Motor Learning As a Function of the Degree of Distribution of Practice," Journal of Experimenta1 Psychology, 39:501-510, August, 1949. 
Leuba and Hyde asked their subjects to learn hand movements requisite to writing German script. Each group of subjects practiced either twice a day, once per day, every two days, or every three days. Using a criterion of the average number of letters written in twenty minutes after five, ten, and fifteen practices, it was discovered that the once a day group was best and the every other day group was second best. 35

Franklin and Brozek selected thirty-six subjects and tested them on gross body reaction time to a light on a treadmill as well as on a pattern-tracing test of eye-hand-foot coordination. Groups practiced under one of the following conditions: three times a day for six days; twice a day for nine days; once a day for eighteen days; three times a week for six weeks; or irregularly for six weeks. Learning curves were similar for all the groups; hence an indication that there was no special advantage in learning efficiency as related to any one form of distribution of practice periods. All the groups showed significant performance improvement in successive trials but there was no difference between the - relatively massed and distributive practices as measured by the total number of practice trials needed to reach a plateau.36

Hardy investigated the effect of various rest intervals on the learning of a stylus maze with 263 subjects who had to achieve a criterion

35 James H. Leuba and Winifred Hyde, "An Experiment in Learning to Make Hand Mcvements," The Psychological Review, 12:351-369, November, 1905.

${ }^{36}$ Joseph C. Franklin and Josef Brozek, "The Relation Between Distribution of Practice and Learning Efficiency in Psychomotor Performance," Journal of Experimental Psychology, 39:16-24, February, 1947. 
of four perfect trials out of five successive runs. He found the four day delay to be an optimum interval and a one day rest the least effective. 37 Snoddy also found learning to be higher in practice under longer time interval rest periods rather than short ones in a mirror tracing task. A pause of twenty-four hours was more profitable than one of two minutes, which in turn was more favorable than a one minute delay, which yielded greater performance than no rest at all. 38

Lorge summarized his studies performed on mirror reading, maze learning, nonsense syllables, and code substitution and found generally that learning under the condition of distribution was more efficient than under the condition of massing. A one-minute and twenty-four hour rest was superior to massed practice for all tasks, with the twenty-four hour break slightly better than the one-minute pause. 39

Using a pursuit-oscillator, Travis administered practice sessions and tests to three groups of college students. He concluded that it was better to have practice periods short, $\underline{\text { e.g. }}$, one minute rather than four minutes, as well as brief inter-practice rests. 40 Bell investigated the effects of various rest intervals on the mastery of a Koerth pursuit rotor task. Four-hundred and fifty-seven subjects were placed into eleven groups

37 Mattie C. Hardy, "The Effect of Distribution of Practice in Learning a Stylus Maze," The Journal of Comparative Psychology, 10:85-96, February, 1930.

${ }^{38}$ Snoddy, op. cit., pp. 1-36.

${ }^{39}$ Irving Lorge, "Influence of Regularly Interpolated Time Intervals Upon Subsequent Learning," Teachers College Contributions to Education, No. $438,1930$.

$40_{\text {Roland C. Travis, "Length of the Practice Period and Efficiency }}$ in Motor Learning," Journal of Experimental Psychology, 24:339-345, March, 1939. 
and all received twenty one-minute trials with one-minute rest periods. The groups were given varied longer rest periods on different trials following the fifth trial. Although there were large gains in scores when the rest intervals were interpolated early in learning, there was little difference between the groups at the end of the twenty trials. 41 Cook and Hilgard gave two groups of twenty-six subjects thirtythree trials on the Koerth pursuit rotor for three consecutive sessions. Group I had decreasing rest periods, beginning with three-minute intervals and ending with twenty-second intervals. Group II practiced under increasing rest conditions. At the completion of practice, there was no significant difference between the groups but greater distribution of practice was found to be more effective both early and late in practice.42

Travis investigated various rest periods between trials on a pursuit oscillator. Five groups of subjects received five-minute learning periods on the oscillator which involved eye-manual coordination on a difficult task. Rest periods varied at five minutes, twenty minutes, forty-eight hours, seventy-two hours, and one-hundred and twenty hours. The rest interval of twenty minutes was discovered to be significantly superior to the others while the five minute pause was second best. Little difference was found in the performance of the subjects who had longer pauses between trials, and Travis therefore concluded that shorter rest

${ }^{41}$ Hugh M. Be11, "Rest Pauses in Motor Learning as Related to Snoddy's Hypothesis of Mental Growth," Psychological Monographs, 54:1-38, 1942.

42 Barbara S. Cook and Ernest R. Hilgard, "Distributed Practice in Motor Learning: Progressively Increasing and Decreasing Rests," Journal of Experimental Psychology, 39:169-172, April, 1949. 
intervals were more effective than longer rest periods. 43

Also using pursuit rotor apparatus, Ammons presented 212 subjects with rests varying from zero, twenty seconds, fifty seconds, two minutes, five minutes, twelve minutes, to twenty-four hours between trials lasting twenty seconds. Best performance was achieved with fifty-second and twominute rest intervals. 44

Doré and Hilgard tested visual-manual coordination of the Koerth pursuit rotor with two groups of subjects who received fourteen trials within forty-three minutes. One group practiced at intervals decreasing from eleven minutes to one minute while the other group practiced at intervals increasing from one to eleven minutes. The latter group proved to be superior in performance. 45 Performing a similar study with the pursuit rotor, Doré and Hilgard had four groups receive forty-three oneminute practice periods with eleven-minute, three-minute, or one minute rests. Instead of only one-minute practice periods, the last group received three-minute work sessions with one-minute rest periods between sessions. Best performance was elicited from the group which had eleven minute rest periods, with a relative decrease in performance shown as the rest periods were shortened. 46

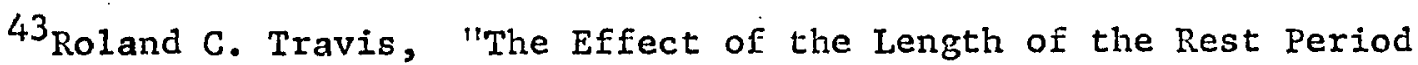
on Motor Learning," Journal of Psychology, 3:189-194, 1937.

${ }^{44}$ Robert B. Ammons, "Acquisition of Motor Skil1: III. Effects of Initially Distributed Practice on Rotary Pursuit Performance," Journal of Experimenta1 Psychology, 40:778-787, December, 1950.

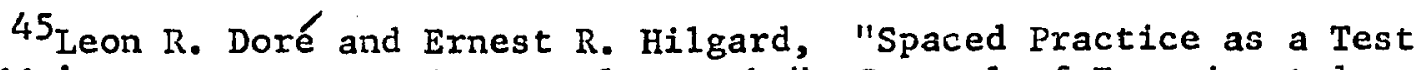
of Snoddy's Two Processes in Mental Growth," Journal of Experimental Psychology, 23:359-374, October, 1938 .

46 Leon R. Doré and Ernest R. Hilgard, "Spaced Practice and the Maturation Hypothesis," Journal of Psychology, 4:245-259, 1937. 
Hilgard and Smith also used the Koerth pursuit rotor and designated three groups to practice under the following conditions: eight trials with three-minute rest periods between trials, thirteen trials with oneminute rests, or eighteen trials with twenty-second rests. In spite of the widely differing number of trials, the three groups scored very much alike at the end of the practice sessions, thus demonstrating the advantage of distributing practice. 47

Pyle demonstrated that two half-hour periods a day for forty-five days yields superior performance to ten half-hour periods a day for nine successive days. Pyle concluded, "Distributed practice is best but the concentrated practice gives good results and if one is in a hurry to acquire a skill, the diminished return for massed practice need not be considered prohibitive." 148

Murphy investigated optimal practice conditions for the acquisition of skill in javelin throwing. Groups practiced either five times a week, three times, or one time a week until a total of thirty-four practice periods were completed. Murphy favored practicing the skill three times or one time a week over five times a week. 49

47Ernest R. Hilgard and M. Brewster Smith, "Distributed Practice in Motor Learning: Score Changes Within and Between Daily Sessions," Journal of Experimental Psychology, 30:136-146, February, 1942. ${ }^{48}$ Pyle, op. cit., pp. 247-258.

${ }^{49}$ Herbert H. Murphy, "Distribution of Practice Periods in Learning," The Journal of Educational Psychology, 7:150-162, January, 1916. 
Young, studying the learning of skill in archery and badminton, found archery to be learned better when practiced four days a week while badminton skill was acquired faster when practiced two days a week. Both groups, in learning these activities, received a total of twenty lessons.50 Knapp and Dixon had thirty-five college students learn how to juggle. One group juggled three balls for five minutes each day while a second group juggled fifteen minutes every second day. Using one-hundred consecutive catches as the criterion for learning to juggle, group one was found to perform much more efficiently. One minute of practice in the first group was found to be equal to one minute and eighty seconds of practice for the second group, therefore demonstrating that shorter practice periods and shorter rest periods are desired conditions of practice. 51

Bilodeau used weighted table tennis balls which had to be inserted into chutes as quickly as possible. Groups received either one, two, four, or eight minute rest intervals between trials, and the final performance scores were found to be related to the length of rest, the greater rest yielded a higher score. 52

Evidently, the optimal rest period necessary for the acquisition of verbal, written, or motor skills varies with the material used. In

50 Olive G. Young, "Rate of Learning in Relation to spacing of Practice Periods in Archery and Badminton," The Research Quarterly, 25:231-243, May, 1954.

${ }^{51}$ Clyde G. Knapp and W. Robert Dixon, "Learning to Juggle: I. A Study to Determine the Effect of Two Different Distributions of Practice on Learning Efficiency," The Research Quarterly, 21:331-336, October, 1950.

52Edward A. Bilodeau, "Perfurmance Decrement In a Simple Motor Task Before and After a Single Rest," Journal of Experimental Psychology, 43:381-390, May, 1952. 
general, thirteen of the studies reviewed here showed superior performance with a greater distribution of practice, eight studies indicated a preference for a rest interval somewhere in the middle of those used, and three investigations did not find any difference in performance with the various intervals employed. However, these results are somewhat misleading as what may have been a minimum rest between trials for one study may have been the maximum rest interval used in another study. No general conclusions may be reached, except perhaps that somewhere between too little rest and too much of a layoff is the desired condition for practice. On the basis of the studies reviewed, it appears that gross motor skills can be learned efficiently with relatively greater spacing of trials than can other types of learning material, e.g., nonsense syllables and pursuit rotors.

\section{RETENTION FOLLOWING MASSED AND DISTRIBUTED PRACTICE}

Of the many studies concerned with massed and distributed practice, most have been primarily interested in the immediate acquisition of material while few have extended the investigation to observe retention effects of the practice conditions.

Cain and willey studied retention following massed and distributed learning of nonsense syllables. One group of subjects learned the list over a three day period while the other group learned the list of syllables in one period. These groups were then subdivided and tested one day, three days, and seven days after the completion of practice. Distributed practice yielded statistically significant better results on all three occasions.53 Also using nonsense syllables, Hovland had a massed practice

53Leo F. Cain and Roy DeVerl Willey, "The Effect of Spaced Learning on the Curve of Retention," Journal of Experimental Psychology, 25:209-214, August, 1939. 
group practice with six second rests between trials while a distributed practice group received two minute rest intervals. Retention was tested after six seconds, two minutes, ten minutes, and twenty-four hours and Hovland found the distributed practice group to perform more efficiently on all these occasions. 54

Archer investigated the course of retention under massed and distributed practice conditions using inverted alphabet writing. Two hundred and forty-three subjects received twenty thirty-second trials either continually, with fifteen-second rests, or with thirty-second rests. In spite of the fact that the distributed practice groups were more superior throughout all the learning trials, after a five-minute lapse, differences between groups, although demonstrating a continued superiority for the distributed practice groups, were nonetheless, not significant.55 Gordon read meaningful material (The Athenian Oath) to four of her classes under massed and distributed conditions. Massed practice resulted in better skill immediately following the readings, but spaced practice proved to be more advantageous in a recall test given four weeks later. 56

${ }^{54}$ Carl I. Hovland, "Experimental Studies in Rote-Learning Theory. VI. Comparison of Retention following Learning to Same Criterion by Massed and Distributed Practice, Journal of Experimental Psychology, 26:568-589, June, 1940 .

${ }^{55}$ E. James Archer, "Postrest Performance in Motor Learning as a Function of Prerest Degree of Distribution of Practice," Journal of Experimental Psychology, 47:47-51, January, 1954 .

56 Kate Gordon, "Class Results with Spaced and Unspaced Memorizing," Journal of Experimental Psychology, 8:337-343, October, 1925. 
Austin found retention of logical reading assignments to be superior under distributed practice when tested for seven, ten, and fourteen days after the completion of practice. In the other part of her experiment, both massed and distributed practice groups performed similarly on recall tests two and twenty-four hours after practice, but the distributed practice group was better on retention tests administered two weeks and one month 1ater. 57

Robinson found digit retention six hours and twenty-four hours after practice to be favored under both massed and distributed practice, depending on the measures employed. 58 Retention of concepts learned, as measured by Oseas and Underwood twenty-four hours after the termination of practice, was especially high with four groups which had had varying rest intervals between trials. 59

Reynolds and Bilodeau, using such apparatus as the rudder control test, a complex coordination test, and a rotary pursuit test, had groups practice under massed and distributed conditions. They were given retention tests ten minutes, fifteen minutes, and ten weeks after the termination of practice, The effects of distributing practice were notably more advantageous throughout the experiment and on the first retention tests, but both groups demonstrated similarity in performance in the retention test given ten weeks later. 60 Using the SAM Complex Coordinator,

57 Austin, op. cit., pp. 370-403.

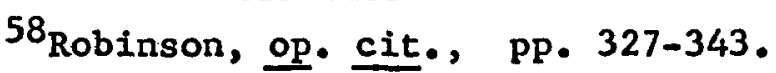

${ }^{59}$ Oseas and Underwood, op. cit., pp. 143-148.

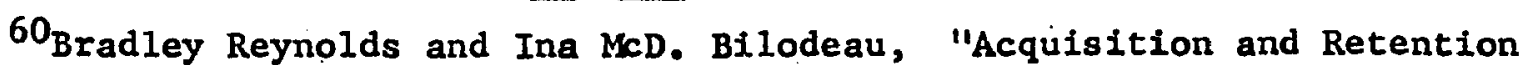
of 3 Psychomotor Tests as a Function of Distribution of Practice During Acquisition," Journal of Experimental Psychology, 44:19-26, July, 1952. 
which requires the subject to match red lights with adjacent green lights by moving a wobble stick and a rudder bar, Lewis and Lowe had one group of subjects continually practice for twenty minutes in each of fifteen sessions. The distributed practice group was allowed thirty-second rests after every trial. Although distributed practice resulted in immediate superior results, a four-month later retention test suggested that the conditions of practice seemed to have no differential effects on retention. 61

Massey had three groups of thirty-two subjects practice tracking with a stabilimeter. One group practiced Monday, Wednesday, and Friday for five weeks, a second group practiced Monday to Friday for three weeks, while a third group of subjects had intermittent practices. No superiority of any one of the patterns investigated was noticed on a retention test given one week at the conclusion of practice. 62

Cook and Hilgard practiced groups of subjects with decreasing and increasing rests between trials on the Koerth pursuit rotor for three days. After long periods of rest, performances tended to be alike, regardless of the arrangement of the prior practice. 63

Although the following studies did not investigate retention after massed and distributed practice, they do demonstrate somewhat the long-term permanence of motor skills practiced under no specific regimen. Swift, using himself as the subject, learned to type over a fifty-day period. Two years elapsed before he touched a typewriter again, and it took him

${ }^{61}$ Don Lewis and William F. Lowe, "Retention of Skill on the SAM Complex Coordinator," Proceedings of the Iowa Academy of Science, 63:591-599, 1956.

62 Dorothy Massey, "The Significance of Interpolated Time Intervals on Motor Learning," The Research Quarterly, 30:189-201, May, 1959.

${ }^{63}$ Cook and Hilgard, op. cit., pp. 169-172. 
only eleven days to reach the same proficiency he had obtained after fifty days.64 Swift had two subjects practice keeping two balls going with one hand, one ball being caught and thrown while the other was in the air. After rest periods of over 600 days, retention tests demonstrated that the subjects in all but two instances performed better than they had at the close of regular practice. 65 Employing the same skill, Swift practiced for forty-two days and then waited six years before he attempted the skill again. It took him only eleven days to relearn the act and demonstrate a performance equivalent to that at the end of the original practice. 66

Studies investigating retention effects after a period of at least twenty-four hours from the final moment of practice have generally found little difference under massed and distributed practice conditions. of the studies reviewed here, seven showed a relative similarity in performances in later tests of retention, four favored distributed practice, and none were found to be more profitable under massed practice.

${ }^{64}$ Edgar J.' Swift, "Memory of Skillful Movements," The Psychology Bulletin, 3:185-187, June 15, 1906.

${ }^{65}$ Edgar J. Swift, "Memory of a Complex Skillful Act," The American Journal of Psychology, 16:131-133, January, 1905.

${ }^{66}$ Edgar J. Swift, "Relearning a Skillful Act: An Experimental study in Neuro-Muscular Memory," The Psychology Bulletin, 7:17-19, January $15,1910$. 


\section{REMINISCENCE AS A FUNCTION OF THE MATERIAL TO BE LEARNED}

Reminiscence has been defined as "an increment in the performance of a partially learned act which is attributable to rest."167 This phenomenon has been demonstrated under various conditions with a variety of learning materials and it seems probable that reminiscence is a widespread occurrence even though there is no completely acceptable evidence of the validity of this statement.

Reminiscence was not isolated as a phenomenon separate from the distribution effects of practice until the work of Ballard in 1913. He read passages from "The Ancient Mariner" for fifteen minutes to elementary school children and then required them to write all that could be remembered. The students were then divided into smaller groups and were tested from one to seven days later. The reminiscence peak was found to be greatest after a two-day delay, as the students remembered more at that point than immediately after the reading. 68

Williams investigated reminiscence effects from the learning of meaningful and non-meaningful material. He tested for retention after rest periods of one, two, three, five, and seven days, finding no reminiscence for the non-meaningful material and some reminiscence for the meaningful material. His results also showed that the subjects who learned the least amount of material during practice demonstrated the

${ }^{67}$ McGeoch and Irion, op. cit., p. 158.

${ }^{68}$ Philip B. Ballard, "Obliviscence and Reminiscence," British Journal of Psychology Monograph Supplements, No. 2, 1913, 88 Pp. 
greatest degree of reminiscence. 69 Newman presented single lists and triple lists of nonsense syllables to two groups of subjects. Reminiscence was not demonstrated with the single list; as 65 percent was retained after the first hour of rest and 50 percent was recalled forty-eight hours later. However, the group that had learned three 1 ists of nonsense syllables, although recalling only 30 percent after the first hour, recalled 40 percent of the lists forty-eight hours later. 70

Noble had twenty-four subjects learn lists of adjectives from a memory drum and did not observe the reminiscence effect. Forgetting took place instead. 71

Many of the investigators concerned with reminiscence have searched for the relationship between specific distributed rest and work intervals and reminiscence; therefore, they will be reviewed in another section of this chapter. Although reminiscence in motor learning has not received a great deal of attention, this is an area in which studies of the distribution of practice have been fairly numerous, and therefore is an area in which the extent of occurrence of reminiscence greatly needs evaluation. Fox and Young instructed two groups of students for six weeks or nine weeks in badminton skilĩs. They were tested after six weeks and twelve weeks of no practice on a wall volley test and short serve test. No reminiscence was noticed in the short service test. The group instructed

${ }^{69}$ Osborne Williams, "A Study of the Phenomenon of Reminiscence," Journal of Experimental Psychology, 9:368-387, October, 1926.

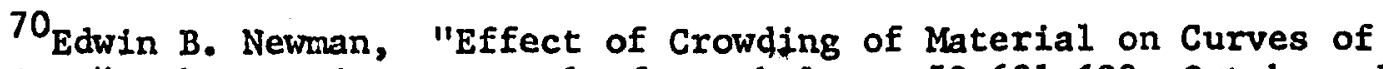
Forgetting," The American Journal of Psychology, 52:601-609, October, 1939.

${ }^{71}$ Clyde $\mathrm{E}$. Noble, "Absence of Reminiscence in the serial Rote Learning of Adjectives," Journal of Experimental Psychology, 40:622-631, October, 1950 . 
for nine weeks did significantly better after six weeks than the group given six weeks' instruction, but after twelve weeks there was no difference between the groups. The former group regressed while the latter group improved and displayed the effects of reminiscence. Evidently, the additional three weeks of instruction did not contribute to 1ong-term retention. 72

Purdy and Lockhart tested subjects one year after they had learned five novel skills, e.g., ball toss and foot volley. These investigators discovered that 89 percent of the subjects displayed reminiscence in one or more of the skills, an incidence of reminiscence much higher than in most other studies. 73

McGeoch 74 and Buxton 75 have summarized the earlier research completed in the area of reminiscence. Buxton believed that reminiscence may be dependent upon a number of factors, some being the type of learning technique employed, type of subject matter, degree of mastery before rest, type of practice (degree of distribution), and the length of the rest interval. The last named factors are the concern of the next two sections in this chapter.

72 Margaret G. Fox and Vera P. Young, "Effect of Reminiscence on Learning Selected Badminton Skills," The Research Quarterly, 33:386-394, October, 1962.

73 Bonnie J. Purdy and Alleene Lockhart, "Retention and Relearning of Gross Motor Skills After Long Periods of No Practice," The Research Quarterly, 33:265-272, May, 1962.

${ }^{74}$ Grace 0 . McGeoch, "The Conditions of Reminiscence," The American Journal of Psychology, 47:65-87, January, 1935.

${ }^{75} \mathrm{Claude} \mathrm{E}$. Buxton, "The Status of Research in Reminiscence," Psychological Bulletin, 40:313-340, May, 1943. 


\section{REMINISCENCE AS A FUNCTION OF THE PREVIOUS DEGREE OF DISTRIBUTION OF PRACTICE}

That one method of distributing practice might be more advantageous for noting the effects of reminiscence is a distinct possibility and one which has been studied by some interested investigators.

Hovland required thirty-two subjects to learn sixteen lists of nonsense syllables through the serial anticipation method. One group was presented with the lists continually, while the other group was allowed two-minute pauses between trials. Following a two-minute rest, reminiscence was obtained with the massed practiced group but not with the distributed practice group. More of the subjects practicing under massed conditions recalled more of the syllables after a rest pause than immediately after learning. 76

In a complex study of the effects of reminiscence, Ward had his subjects learn nonsense syllable lists with intervals ranging from six seconds to twenty minutes. Retention tests were given after thirty seconds, two minutes, five minutes, ten minutes, and twenty minutes. The average retention scores showed to a marked degree the phenomenon of reminiscence with more retention noted with the groups that had shorter rest periods. 77

Hovland and Kurtz tested the effects of prior mental practice on the learning of nonsense syllables. Twelve subjects received twelve sessions a day for six days and were tested later for any signs of

76 Carl I. Hovland, "Experimental Studies in Rote-Learning Theory. I. Reminiscence Following Learning By Massed and By Distributed Practice," Journal of Experimental Psychology, 22:201-224, March, 1938.

77 Lewis B. Ward, "Reminiscence and Rote Learning,!" Psychological Monographs, 49:1-64, 1937. 
reminiscence. The control group, which did not receive any mental work prior to practice, performed worse on the later test while the group which had continuous mental work followed by learning demonstrated absolute reminiscence. A third group, which had mental work and then a two minute rest preceeding learning, did not demonstrate any reminiscence. Evidently," reminiscence effects may sometimes be attributable to a difference in prior activity of the subjects before beginning a learning series.78

In an early investigation, Perkins had four subjects learn fourteen syllables grouped in pairs in sets of sixteen repetitions. Each subject practiced either one, two, four, or eight sets at a time with intervals of either one, two, three, or four days. Perkins found that the smaller number of sets used at a session resulted in a higher percentage of success. Also, less syilables were recalled when they were presented every day instead of at certain intervals. A three day interval appeared to be most favorable for reminiscence. 79

Underwood studied reminiscence resulting from massed practice serial learning of consonant syllables. The reminiscence interval was only. two minutes and was introduced either early or later in the practice trials. Instead of reminiscence, forgetting was observed over all two-minute rest intervals.80 McClelland also investigated as to whether a two-minute rest

${ }^{78}$ Carl I. Hovland and Kenneth H. Kurtz, "Experimental Studies in Rote-Learning Theory: IX. Influence of Work-Decrement Factors on Verbal Learning," Journal of Experimental Psychology, 42:265-272, October, 1951.

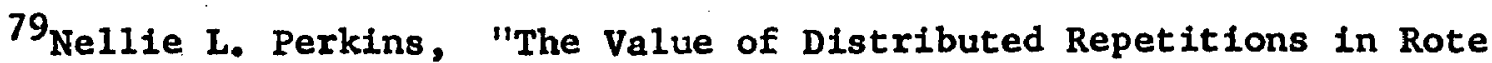
Learning," British Journal of Psychology, 7:253-261, September, 1914.

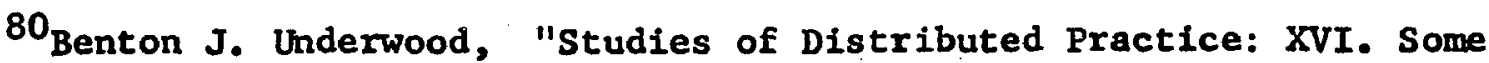
Evidence on the Nature of the Inhibition Involved in Massed Learning of Verbal Materials," Journal of Experimental Psychology, 54:139-143, August, 1957. 
interval was sufficient enough time to allow reminiscence to take place. However, he presented lists at a four-second rate to forty-eight subjects and at a two-second rate to another group of forty-eight subjects. No reminiscence was found after a two minute rest if the rate of presentation was four seconds but it was noticeable if the rate was two seconds, thus indicating reminiscence effects following relatively massed practice. 81

Kimble had five groups learn to print the alphabet upside down receiving either zero, five, ten, fifteen, or thirty second rest pauses between trials. The shortest inter-trial rests resulted in the most reminiscence. However, after a ten-minute rest period, all groups were about even. 82

Little has been done in the field of motor learning concerning the effects of distribution of practice or reminiscence. The only representative studies of motor learning in this area of learning have dealt with pursuit rotor tasks. Irion tested reminiscence after a five minute delay ' following varying amounts of prerest practice on the Koerth pursuit rotor. He found significant reminiscence on all relearning trials.83 Jahnke and Duncan studied massed and distributed effects on the acquisition and retention of a rotary pursuit task. They found reminiscence continuing to increase until at least one day following practice for the massed practice group. 84

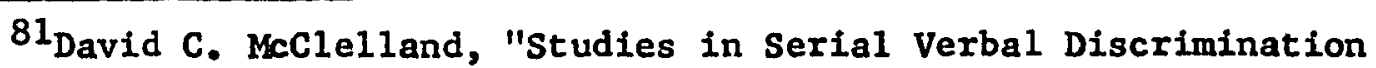
Learning. I. Reminiscence with Two Speeds of Pair Presentation," Journal of Experimental Psychology, 31:44-56, July, 1942.

${ }^{82}$ Kimble, op. cit., pp. 501-510.

${ }^{83}$ Arthur L. Irion, "Reminiscence in Pursuit-Rotor Learning As A Function of Length of Rest and of Amount of Pre-Rest Practice," Journal of Experimental Psychology, 39:492-499, August, 1949.

84 John C. Jahnke and $\operatorname{Car} 1$ P. Duncan, "Reminiscence and Forgetting in Motor Learning After Extended Rest Intervals," Journal of Experimental Psychology, 52:273-282, November, 1956. 
Jahnkè had groups receive varying amounts of prerest trials, rest for forty-eight hours, then presented with additional trials on the pursuit rotor. The groups receiving the smallest amount of prerest distribution of practice showed the greatest amount of reminiscence and therefore Jahnke concluded that reminiscence is an inverse monotonic function of the amount of prerest distribution of practice. 85

Duncan provided his subjects with twenty-minute practice sessions on a rotary pursuit task. Even though the distributed practice group had only one-third as much actual practice as the massed practice group, the distributed group did significantly better immediately after the practice. Both groups displayed reminiscence on a later test, with no difference demonstrated between the two. 86

In general it appears as if relative massing of trials will afford the greatest amount of reminiscence which in turn will result in a similar performance or in a performance slightly below that of a distributed practice group. A possible explanation is that at the immediate conclusion of practice, the distributed practice usually yields a superior performance to the massed but after a rest period the distributed group performs slightly poorer, the massed group better, and therefore both ultimately approximately equal. A more detailed possible theoretical explanation of the occurrence will be presented in the last section of this chapter.

${ }^{85}$ John C. Jahnke, "Postrest Motor Learning Performance as a Function of Degree of Learning," Journal of Experimental Psychology, 62:605-611, December, 1961 .

${ }^{86}$ Carl P. Duncan, "The Effect of Unequal Amounts of Practice on Motor Learning Before and After Rest," Journal of Experimental Psychology, 42:257-264, October, 1951. 


\section{REMINISCENCE AS A FUNCTION OF THE LENGTH OF THE REST INTERVAL}

How long after the termination of practice the performance increases is a question of considerable importance. Experimenters have used various methods and materials in an attempt to discover the answer to this question. According to Bunch, the method most used in measuring reminiscence is a comparison of the skill produced after. a specified interval of time with the amount recalled immediately following the formal practice. 87

Ward tested reminiscence thirty seconds, two minutes, five minutes, ten minutes, and twenty minutes following the learning of nonsense syllables. The two-minute rest was most effective (ten percent more recalled than Immediately after practice). Reminiscence effects fell off after five minutes and at ten and twenty minutes forgetting had set in.88 underwood in his study using serial consonant syllables, did not find any reminiscence with a two-minute pause, the only interval he employed. 89 However, McClelland noticed reminiscence effects with a two-minute interval if the lists were presented at the rate of two seconds instead of four seconds.90 Ballard tested groups of children from one to seven days after they had learned poetry and found the reminiscence peak to be highest at two days. 91

${ }^{87}$ M. E. Bunch, "The Measurement of Reminiscence," The Psychological Review, 45:523-531, November, 1938.

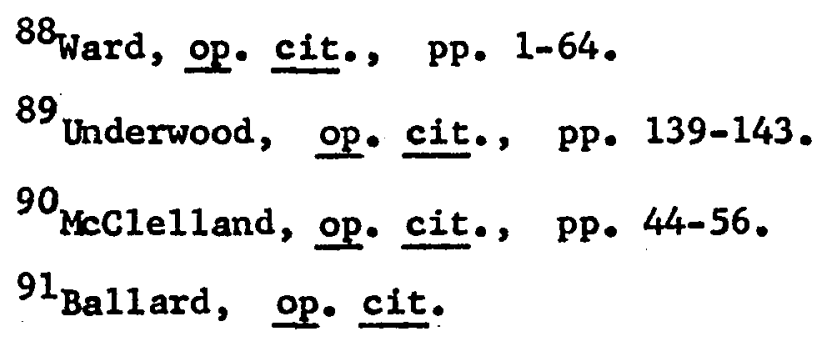


E11is et al., using a task whereby subjects had to turn blocks over in holes, tested for retention two minutes, ten minutes, and twentyfour hours following practice. They found the ten-minute pause to be favored for reminiscence over the other two rest intervals. 92

Ammons investigated the problem with 510 women as subjects. Using various amounts of practice on the pursuit rotor and varying amounts of rest before testing for retention from twenty seconds to 360 minutes, Ammons discovered reminiscence to reach maximum value after a five-minute rest.93 Jahnke and Duncan, using 440 males to learn a rotary pursuit task, found the effects of reminiscence to continue until at least twenty-four hours after practice. 94

Irion, also employing the pursuit rotor, varied the length of rest up to five minutes after practice. He found reminiscence to be a function

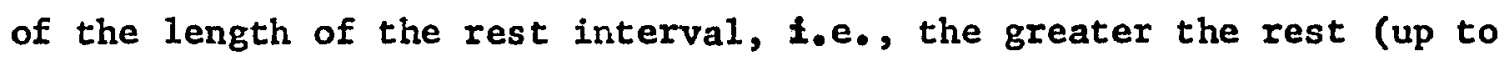
five minutes), the greater the reminiscence. Kimble and Horenstein gave ninety-three subjects ten practice trials each on a modified Koerth pursuit rotor. Retention tests were given at either ten, thirty, 150,600 , or 1200 seconds after practice, with results extremely similar to those found by Irion. There was an increase in reminiscence up to 600 seconds and the rest thereafter proved ineffective. 96

92Douglas S. E11is, Victor Montgomery, and Benton J. Underwood, "Reminiscence in" a Manipulative Task as a Function of Work-Surface Height, Prerest Practice, and Interpolated Rest," Journal of Experimental Psychology, 44:420-427, December, 1952.

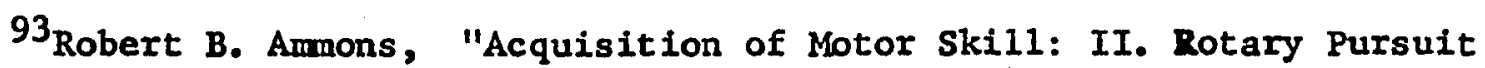
Pefformance with Continuous Practice Before and After a Single Rest," Journal of Experimental Psychology, 37:393-411, October, 1947.

94 Jahnke and Duncan, 으. cit., pp. 273-282.

95Irion, op. cit., pp. 492-499.

96 Gregory A. Kimble and Betty R. Horenstein, "Reminiscence in Motor Learning as a Function of Length of Interpolated Rest," Journal of Experimental Psychology, 38:239-244, June, 1948 . 
Employing a ball tossing skill whereby the subject tossed and caught two balls so that one would always be in the air, Batson gave five subjects practice over a two-month period and tested for short-term and long-term retention. After a short period (one or two days), there was no regularity in scores as sometimes they were higher, sometimes lower than at the completion of practice. After a rest period of six months or a year, the subjects improved very quickly in their relearning of the skill and, in some cases, actually demonstrated a gain during the rest period from the preceding test. 97

Fox and Young, testing selected badminton skills, demonstrated reminiscence after a six-week rest interval with a group that had received nine weeks of instruction and reminiscence following a twelve-week pause with a group that had had six weeks of instruction:98

Fox and Lamb studied the effects of reminiscence following the learning of softball skills. No reminiscence was demonstrated after a five-week period of no practice, but improvement in skill was noticeable after a seventeen-week layoff. 99

Studies investigating an optimal period for the demonstration of reminiscence effects have shown these periods to vary with the to-belearned material, from a few minutes with nonsense syllables to a few months with athletic skills.

97William H. Batson, "Acquisition of Skill," Psychological Monograph, 21:1-94, July, 1916.

98 Fox and Young, op. c1t., pp. 386-394.

99 Margaret G. Fox and Ethel Lamb, "Improvement During a Nonpractice Period in a Selected Physical Education Acttvity," The Research Quarter1y, 33:381-385, October, 1962. 


\section{THEORIES OF REMINISCENCE AND THE DISTRIBUTION EFFECT}

Through the years many theories have been advanced in an attempt to explain and predict performance during and after massed and distributed practice. Some have been upheld better than others from the findings of experimental research, and McGeoch has reviewed the possible theories and categorized them as follows: work theories, perseveration theories, and differential forgetting theories. 100

According to McGeoch, differential forgetting theories generally handle massed and distributed practice effects by stating that during practice a subject learns incorrect and conflicting responses as well as correct ones. 101 Because the conflicting associations are probably less well learned than the appropriate responses, the conflicting ones would dissipate with rest at a faster rate than during practice. Therefore, according to the theory, learning would take place faster during distributed practice because the incorrect responses would have an opportunity to drop out more quickly than under massed practice conditions. However, there are theoretical limitations as to the desirable length of the rest interva1.

Reminiscence would be explained in a similar manner: rest intervals provide an opportunity for the dropping out or forgetting of wrong associations which are less strongly favored than the right ones and hence are forgotten more rapidly. Under. this theory, massed practice would probably be expected tó yield a greater reminiscence effect than distributed practice.

$$
\begin{aligned}
& 100_{\text {McGeoch, op. cit., pp. 171-189. }} \\
& 101_{\text {Ibid., pp. } 183-188 .}
\end{aligned}
$$


Perseveration theories tend to hold that some activity persists in the individual after the termination of practice, therefore resulting in the learned response becoming more strongly fixated than it was previously. Muller and Pilzecker formulated the classical perseveration theory, and Hovland explains it as follows: "The neural processes perseverate for a considerable time following learning. Distributed practice permits the setting-in process to proceed with minimal interference," while massed practice would not allow enough time to permit this activity, to occur. 102 Work theories generaliy state that the act of repeating a response tends to build up either a loss of interest, boredom, physical fatigue, or mental fatigue. The interfering processes supposedly disappear with rest and the more permanent learned responses wopld supposedly remain.

Hull's theory, based on a theoretical construct called reactive inhibition, is most representative of the work theories and probably has instigated more investigations in the area of massed versus distributed practice than any other theory.103 Hull postulates that there are two inhibitory processes which occur when responses are made, reactive inhibition $\left(I_{R}\right)$ and conditioned inhibition $\left(S^{I_{R}}\right) . I_{R}$ is temporary by nature and dissipates with time while $S^{I_{R}}$ is relatively permanent. The temporary work decrement increases with increased practice and would explain the poorer performance of subjects learning under massed practice conditions. By the ' same token, distributed practice would"permit $I_{R}$ effects to disappear more easily; hence, the superior performance of distributed practice subjects.

$$
\begin{aligned}
& { }^{102} \text { Hovland, op. cit., p. } 183 . \\
& 103_{\text {Hull, op. cit., pp. } 276-287}
\end{aligned}
$$


Also, reminiscence is described as occurring when the $I_{R}$ effects have been rendered ineffective as a result of rest from repeating the desired responses.

As was mentioned previously, many studies have been formulated in an attempt to discover the application of Hull's theory to actual performance, and Ellis discusses the reactive inhibition theory in light of the studies completed. 104 Ward, testing retention after thirty seconds, two minutes, five minutes, ten minutes, and twenty minutes, found the two-minute interval to be most desirable for reminiscence. He explains, in Hullian terms, that there was a rapid dying out of inhibitory tendencies built up during learning, with the correct responses thereby becoming more free to function. 105 On the other hand, Underwood used only a two minute rest interval as a retention test after massed practice and did not locate any signs of reminiscence. He concluded,."If a depressing inhibition is postulated to account for poorer performance under massed than under distributed practice, the inhibition cannot be assigned rapidly dissipating properties."106

Kimble and Horenstein, using five intervals for testing retention, found the five-minute rest pause most effective for demonstrating reminiscence. They felt that the study verified Hull's theoretical formulation of the decay of inhibition as a function of time.107 Irion, using the pursuit rotor, also found the five-minute rest interval to allow for the greatest reminiscence. 108

${ }^{104}$ Douglas S. Ellis, "Distribution Theory and the Effort Variables," Psychological Review, 60:383-392, November, 1953.

105 Ward, op. cit., pp. 1-64.

${ }^{106}$ Underwood, 으. it., pp. 139-143.

107 Kimble and Horenstein, op. cit., pp. 239-244. ${ }^{108}$ Irion, op. cit., pp. $492-499$. 
When a subject learns under relatively massed practice, supposedly an inhibition develops which hinders performance rather than learning. Therefore, performance would be weaker under massed conditions rather than under distributed practice since the inhibition dissipates rapidly with rest. Just what the optimal rest period is for superior performance has been disputed as a result of the findings of various studies.

Jahnke and Duncan, after reviewing the results of their study, felt that $I_{\mathbf{R}}$ continues to dissipate over a longer period than a ten or twenty minute rest. Also, they stated that the habit strength (HS) is not the same under massed and distributed practice. They accounted for the superior performance of a distributed practice group over a massed practice after a four-week interval even though the performance difference was less with increased rest as due to a continued partial recovery from the $I_{R}$ with rest which was not quite enough to reach the level of the distributed practice group.109 Hovland accounts for the superior retention of distributed practice subjects by the supposition that the strongly established interferences would impair recall for a considerable period following massed practice. Retention would be superior following distributed practice where fewer strong interferences are assumed to be established.110 Newman's results also disagree with previous studies which point to a very short period immediately following any learning process as being the period when one might expect to find the most reminiscence. He found reminiscence to be greatest after a forty-eight hour rest interval, and concluded that the

109 Jahnke and Duncan, op. cit., pp. 273-282. 110 Hovland, op. cit., pp. 568-589. 
interfering effect on inhibition produced by massing the practice decreases to some extent with the passage of time, taking place possibly two minutes after learning, over a period of twelve minutes, or over a period considerably greater than one hour. 111

Kimble 112 and Ammons 113 have applied Hull's basic concepts to motor skill learning, more specifically, rotary pursuit learning. Kimble calls his theory a "Two-Factor Theory of Inhibition."114 Ammons favors Kimble's theory and states that in many studies rest. periods are too short to allow for the dissipation of the majority of the reactive inhibition. 115

Gagne and Fleishman believe that the inhibition affects performance rather than what is learned. They write concerning motor skills:

If one concentrates the learning of a motor skill..., we have no reason to believe that this is a particularly inefficient learning procedure, although its effects on immediate performance may be detrimental. 116

Evidently, the amount of effort exerted by the subject in learning will have its effects on performance. $117 \mathrm{Kimble}$ assumes that the more effortful behavior will result in a greater amount of $I_{R}$ present and therefore a greater need to cease activity. Effortfulness would depend on the physical energy required for the learning of the task and the

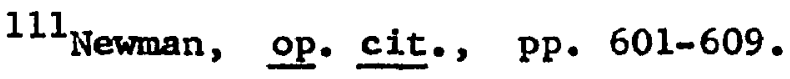

112 Kimble and Horenstein, op. cit., pp. 239-244. 113 Ammons, op. cit., pp. 393-411.

114 Gregory A. Kimble, "An Experimental Test of a Two-Factor Theory of Inhibition," Journal of Experimental Psychology, 39:15-23, February, 1949

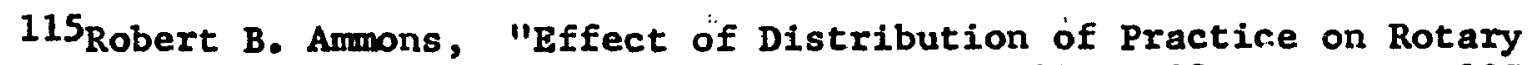
Pursuit Hits," Journal of Experimental Psychology, 41:17-22, January, 1951.

116 Robert M. Gagne and Edwin A. Fleishman, Psychology of Human Performance (New York: Henry Holt and Company), $1 \overline{959 .}$

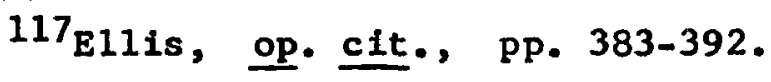


length of time without rest while practicing. 118

Since greater overall bodily effort is required for the mastery of athletic skills as contrasted to learning nonsense syllables or rotary pursuit tasks, possibly this may be one of the reasons why reminiscence has been demonstrated after twelve weeks of no practice on athletic skills.119 Massed practice would theoretically be more ineffective with the learning of gross motor skills than other learning materials because of the effort involved. On the same explanatory grounds, reminiscence should then be greater after practicing these gross motor skills.

Hovland feels that verbal learning can be explained in terms of associative interferences, while in motor learning, work decrement factors (motivation, boredom, physical fatigue) have to be stressed with the possible supplementation of the reactive inhibition concept. 120

Sumary of the Review of Literature. Of the many studies which are found in the experimental literature, the vast majority have demonstrated the immediate superiority of distributed practice over massed practice using a wide range of learning materials and methods. As to the optimal rest interval between trials, wide variations are found depending on the task employed. It would probably be safe to assume that rest periods should not be too brief nor too extensive, and that some learning materials are learned more effectively over relatively greater rest intervals than others.

$$
\begin{aligned}
& { }^{118} \text { Kimble, op. cit., pp. 501-510. } \\
& { }^{119} \text { Fox and Young, op. cit., pp. } 386-394 . \\
& { }^{120} \text { Hovland and Kurtz, op. cit., pp. } 265-272 \text {. }
\end{aligned}
$$


Little difference may be found in the eventual retention of a learned task which has been practiced under continuous and spaced practice, although there is a slight inclination to favor distributed practice for retention success.

Reminfscence has been obtained in many studies investigating for the occurrence of this phenomena. It is not limited to a specific task or under a special learning condition, although it appears as if massed practice tends to lead to greater reminiscence effects. Although reminiscence may raise the performance level of previously massed practiced subjects, distributed practice subjects still fare as well, if not better, on retention tests of the permanence of the acquired tasks.

Reminiscence has been demonstrated following numerous rest intervals; from two minutes to one year after the termination of practice. Gross motor skills appear to lend themselves to greater reminiscence over a longer period of time than such materials as nonsense syllables and fine motor skills. It is conjectured that possibly the effort variable may partially cause this occurrence.

- From a theoretical point of view, it seems as if the reactive inhibition theory, constructed by Hull and advanced by Kimble and Ammons may explain the results of massed and distributed practice on motor skill learning better than other theories proposed. The massing of practice trials depresses the level of performance because of the buildingup of inhibition ( $I_{R}$ and $s I_{R}$ ). However, with rest, the $I_{R}$ dissipates and the performance level recovers. Apparently, the massing of trials affects immediate performance rather, than the learning process itself. 


\section{CHAPTER III}

\section{PROCEDURES}

The purpose of this study was to compare the effects of massed and distributed practice on skill acquisition and retention. The procedures used to obtain the desired information included the selection of subjects, instruction of the skill to be learned, practice sessions, and a comparison at various intervals of three groups of subjects that practiced the skill under different rest interval conditions. The skill was taught, practiced, and tested in the mens' gymasium, located in the Physical Education Building at The Ohio State University.

\section{Selection of Subjects}

One-hundred and twenty male freshman students enrolled in the required physical education program at The Ohio State University served as subjects for the study. These students were volunteers from the classes in which the writer instructed during the spring and autumn quarters, 1963. Subjects were chosen for not having had any or having had very little previous experience in performing the to-be-learned skill. Subjects with previous experience in this specific skill were eliminated from the study.

\section{Novel Skill Learned}

An unusual basketball skill, not usually practiced, was the skill learned by the subjects in this study. For this skill, each subject was required to stand behind the foul line, which is fifteen feet from the 
basket. He held the ball with both hands and attempted to bounce the basketball off the floor and into the basket, which stands ten feet above the gymasium floor. The attempt was considered good whether it went directly through the rim or off the backboard and then through the rim. It should be pointed out that this skill is extremely difficult to master, even for those very experienced in the game of basketball.

Because of the difficulty involved in acquiring skill in bouncing the ball off the floor and into the basket and in order to reward those subjects who came close to scoring an attempt, a point system was decided upon which awarded five points for a basket, three points for a "rimmer" (ball which spins around the rim and just misses going in), and one point for hitting the rim. It was felt that this system would be more representative of the participant's success in performing the skill than merely just acknowledging a score.

The bounce-ball-in-basket skill was selected as the skill to be used in this study for four reasons. First, it is a gross motor skill, involving certain large muscles of the body. Practically all previous studies in the area of distribution of practice concerned with the physical movements of the body have dealt with fine motor skills (eye-hand coordination). Second, the skill is not only novel, but it also contains a certain degree of challenging difficulty. Third, it is a skill not usually practiced and one which would allow the subjects to play the game of basketball during the experimental period while not affecting the results of the study. Fourth, it is a skill easy to score, not open to an evaluator's personal subjective judgment. 


\section{Administration of the Practice}

The 120 subjects were divided into three groups of 40 on the basis of the number of successful shots made in the first twenty attempts. In order to obtain initlal homogenelty of the groups, high scorers and low scorers were equally allocated to the three groups.

Group A practiced the bounce-ball-in-basket skill under massed conditions and continually shot at the basket until eighty attempts were completed. Group B shot twenty times and rested five minutes afterwards and repeated this process until fulfilling the eighty shot obligation. Group C rested twenty-four hours after each of four twenty-attempt clusters.

The subjects practiced in pairs; one shooting and the other tallying the points and retrieving the ball. Three basketballs, each containing the same air pressure and each numbered, were used in the study. All students were instructed to use the same ball and the same basket at every practice session and eventual testing periods in order to minimize any possible differences between basketballs or between baskets.

The three groups were tested upon the immediate conclusion of their practice periods. Groups $A, B$, and $C$ were randomly divided in half with $A_{1}, B_{1}$, and $C_{1}$ being tested the next day whereas $A_{2}, B_{2}$, and $C_{2}$ were tested seven days after the completion of practice.

It was decided that test trials could also be considered practice periods and therefore might confuse the results obtained in the study. A massed practice group, if tested the following day and following week would actually have received a distributed practice (the next day test) along with the massed practice. Also, according to Buxton, when investigating 
the effects of reminiscence, more than one retention test to any group of subjects actually gives them more practice at their task, so that what may seem like reminiscence may only be improvement through additional practice.1 In order to avoid these complications it was necessary to have separate sample groups, tested at these intervals.

A11 groups were tested one month after the termination of the practice trials. Each test included twenty attempts at the basket and was scored on the 5-3-1 basis previously mentioned in this chapter. No warm-ups were allowed prior to the testing, nor was practice allowed between test periods.

Statistical analysis was applied to the practice learning curves to see whether the curves were distinct and specific to their particular practice measures. The groups were compared with each other at the different intervals of time mentioned earlier and the results were analyzed in order to distinguish statistically any differences that might have been shown. Each group was compared with itself on succeeding test trials'so as to note retention and any possible effects of reminiscence.

${ }^{1}$ Claude E. Buxton, "Reminiscence in the Acquisition of Ski11," Psychologlcal Review, 49:191-196, March, 1942. 


\section{CHAPTER IV}

\section{ANALYSIS OF DATA}

It is the purpose of this chapter to statistically analyze between group and within group changes that occurred during practice of the bounce-ball-in-basket skill and eventual tests of retention. One-hundred and twenty male freshman students were distributed equally into three groups. Group A practiced under massed conditions and continually shot at the basket until eighty attempts were completed. Groups B and C practiced under distributed conditions, with B resting five minutes and $C$ pausing twenty-four hours after each of four twentyattempt groupings.

\section{Acquisition of the Skill}

Since the groups were treated identically during attempts one to twenty, a comparison of the groups for this block of shots would indicate whether the original assignments of subjects resulted in comparable groups. An analysis of variance test for homogeneity is presented in Table 1, page 57, and indicates extreme homogeneity between groups at the beginning of practice. It is clear that the three groups did not differ significantly because of the manner in which the subjects were assigned to their groups. 
TABLE 1

ANALYSIS OF VARIANCE TEST FOR HOMOGENEITY OF GROUPS**

Summary of Analysis of Variance

\begin{tabular}{lrrrr}
\hline Source of variation & df & SS & MS & $F^{*}$ \\
\hline Between treatments & 2 & 20 & 10 & .13 \\
Within treatments \\
Total & $\underline{117}$ & $\underline{9051}$ & 77 &
\end{tabular}

*An $\mathrm{F}$ based on 2 and 117 degrees of freedom must be 3.08 or larger to be significant at the .05 level.

**Based on first 20 attempts.

The mean scores and standard deviations of the three groups throughout practice and on a test immediately following practice are shown in Table 2. The results are presented in terms of the number of points scored on every twenty attempts at the basket.

Winer states that if a subject is observed more than once, a special type of analysis of variance ( $F$ test) called repeated measures should be employed when analyzing the data. 1 In experiments designed to

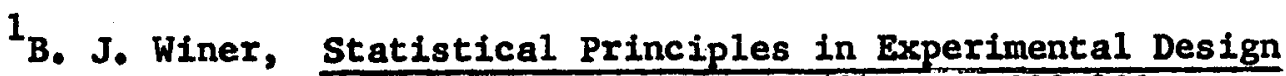
(New York: McGraw-Hil1 Book Company, Inc., 1962), PP. 298-301. 
TABLE 2

MEAN SCORES AND STANDARD DEVIATIONS FOR MASSED AND DISTRIBUTED GROUPS EACH TWENTY TRIALS DURING PRACTICE

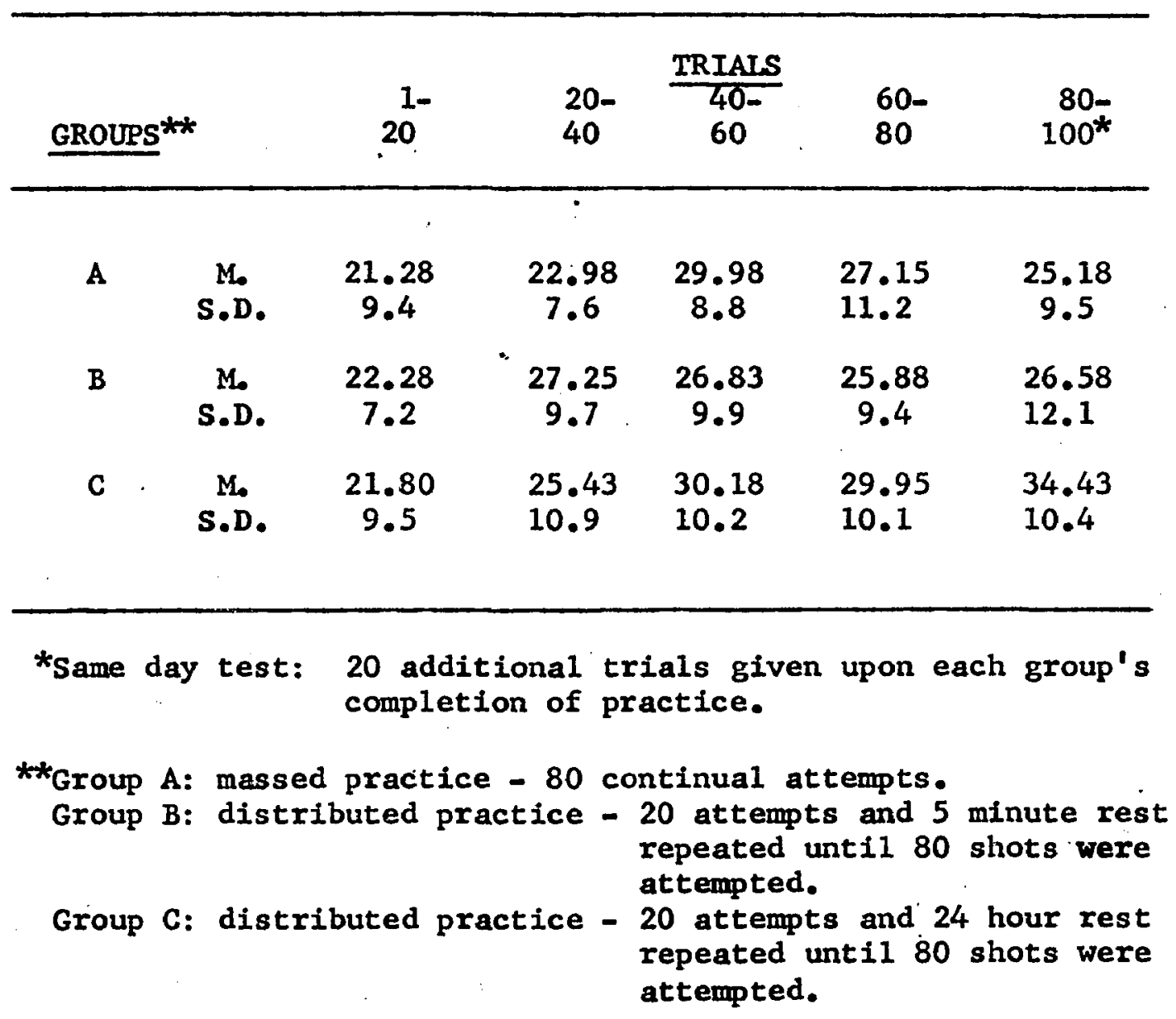


study learning as a function of treatment effects and the treatments are administered in succession to the same subject instead of to different groups of subjects, he proposes the repeated measures technique mainly because of the control that this kind of design provides over individual differences betwen exporimental units. Lindquist favors its use in order to increase the precision of the experiment by eliminating inter-subject differences as a source of error. ${ }^{2}$

Table 3, page 60, contains an analysis of variance of repeated measures on the practice and end of practice test trials as suggested by Winer. 3 The significant main effect for factor $B$ indicates that the subjects' socres changed from trial to trial (each twenty attempts at the basket is considered a trial). The significant $A B$ interaction Indicates that the effect of the test trials was different in the massed and distributed practice groups. The data also suggest that the shapes of the learning curves are essentially different under the massed and distributed practice conditions.

Because the $F$ test only determines general significance and does not indicate which or how many means are significant, it is necessary to utilize a measure which would provide such necessary information. The use of multiple t tests is frowned upon because the protection level across a sequence of tests is raised.

2E. F. Lindquist, Design and Analysis of Experiments in Psychology and Education (Boston: Houghton Miffin Co., 1953), Pp. 156-166.

3iner, op. cit., pp. 305-308. 
TABLE 3

ANALYSIS OF VARIANCE OF PERFORMANCE DURING PRACTICE

Summary of Analysis of Variance

\begin{tabular}{|c|c|c|c|c|}
\hline Source of variation & $d f$ & SS & MS & $\mathbf{F}$ \\
\hline Between Subjects & 119 & 32599.0 & & \\
\hline Practice conditions & $(A) 2$ & 1093.7 & 546.9 & 2.03 \\
\hline Subjects w. groups & 117 & 31505.3 & 269.3 & \\
\hline Within Subjects & $\underline{480}$ & 31398.0 & & \\
\hline Test trials (B) & 4 & 4451.9 & 1129.8 & $21.12^{* *}$ \\
\hline$A B$ & 8 & 1905.7 & 238.2 & $4.45^{*+2}$ \\
\hline B X Subj. w. groups & 468 & 25040.4 & 53.5 & \\
\hline
\end{tabular}

${ }^{* *}$ Significant at the .01 level. 
Therefore, a sequential test on ordered means of the practice. and end of practice test trials was computed by using the Duncan Multiple Range Test. 4 Means are arranged in rank order from low to high and differences between all possible pairs of ordered means are computed. A mean difference score in a particular column has to be as high as or higher than the corresponding reference $X$ standard error value in order to be significant at the .05 leve1. The results of this test are indicated in Table 4.

In analyzing within group differences, Group A (massed practice) did statistically better on attempts forty-one to sixty $(M=29.98)$. than they did on their first twenty attempts $(M=21.28)$ and on the end of practice test $(M=25.18)$. Although there was a decrease in performance following attempts forty-one to sixty, scores were still significantly superior to the initial twenty attempt scores.

Group B (five-minute rests) reached its highest peak on attempts twenty-one to forty. The difference between the means of attempts one to twenty $(M=22.28)$ and twenty-one to forty $(M=27.25)$ were significant at the .01 level. Means on the following trials were not significantly different from trial two, although all were significantly higher than the first trial of twenty attempts.

Group C (twenty-four hour rests), with the exception of attempts sixty-one to eighty, performed significantly better on succeeding trials following the first twenty attempts.

${ }^{4}$ David B. Duncan, "Multiple Range and Multiple F Tests," Biometrics, 2:1-42, March, 1955. 
TABLE 4

DUNCAN MULTIPLE RANGE TEST ON ORDERED MRANS TO DETERMINE SIGNIFICANCE OF THE DIFFERENCES BETWEEN MRANS OF GROUPS EVERY TWENTY TRIAIS DURING PRACTICE

\begin{tabular}{|c|c|c|c|c|c|c|c|c|c|c|c|c|c|c|}
\hline 1 & 2 & 3 & 4 & 5 & 6 & $\begin{array}{c}\text { Order } \\
7\end{array}$ & $\begin{array}{c}\text { d Means } \\
8\end{array}$ & 9 & 10 & 11 & 12 & 13 & 14 & 15 \\
\hline \multirow[t]{2}{*}{21.28} & 21.80 & 22.28 & 22.98 & 25.18 & 25.43 & 25.88 & 26.58 & 26.83 & 27.15 & 27.25 & 29.95 & 29.98 & 30.18 & 34.43 \\
\hline & .52 & $\begin{array}{r}1.00 \\
.48\end{array}$ & $\begin{array}{r}1.70 \\
1.18 \\
.70\end{array}$ & $\begin{array}{l}3.90 \\
3.37 \\
2.85 \\
2.20\end{array}$ & $\begin{array}{r}4.15 \\
3.62 \\
3.10 \\
2.45 \\
.25\end{array}$ & $\begin{array}{r}4.60 \\
4.07 \\
3.55 \\
2.90 \\
.70 \\
.45\end{array}$ & $\begin{array}{r}5.30 \\
4.77 \\
4.25 \\
3.60 \\
1.40 \\
1.15 \\
.70\end{array}$ & $\begin{array}{r}5.55 \\
5.02 \\
4.55 \\
3.85 \\
1.65 \\
1.40 \\
.95 \\
.25\end{array}$ & $\begin{array}{r}5.87 \\
5.35 \\
4.87 \\
4.17 \\
1.97 \\
1.72 \\
1.27 \\
.57 \\
.32\end{array}$ & $\begin{array}{r}5.97 \\
5.45 \\
4.97 \\
4.27 \\
2.07 \\
1.82 \\
1.37 \\
.67 \\
.42 \\
.10\end{array}$ & $\begin{array}{l}8.67 \\
8.15 \\
7.67 \\
6.97 \\
4.77 \\
4.52 \\
4.07 \\
3.37 \\
3.12 \\
2.80 \\
2.70\end{array}$ & $\begin{array}{r}8.70 \\
8.18 \\
7.70 \\
7.00 \\
4.80 \\
4.55 \\
4.10 \\
3.40 \\
3.15 \\
2.83 \\
2.73 \\
.03\end{array}$ & $\begin{array}{r}8.90 \\
8.38 \\
7.90 \\
7.20 \\
5.00 \\
4.75 \\
4.30 \\
3.60 \\
3.35 \\
3.03 \\
2.93 \\
1.23 \\
.20\end{array}$ & $\begin{array}{r}13.15 \\
12.63 \\
12.15 \\
11.45 \\
9.25 \\
9.00 \\
8.55 \\
7.85 \\
7.60 \\
7.28 \\
7.18 \\
4.48 \\
4.45 \\
4.25 \\
\end{array}$ \\
\hline
\end{tabular}

Rejection

\begin{tabular}{|c|c|c|c|c|c|c|c|c|c|c|c|c|c|c|}
\hline lue $(.05$ leve 1$)$ & 2.77 & 2.92 & 3.02 & 3.09 & 3.15 & 3.19 & 3.23 & 3.26 & 3.29 & 3.315 & 3.34 & 3.36 & 3.38 & 3.395 \\
\hline $\left.\operatorname{Re} j_{\bullet}\right)\left(S_{E}\right) *$ & 3.21 & 3.39 & 3.50 & 3.58 & 3.65 & 3.70 & 3.75 & 3.78 & 3.82 & 3.85 & 3.87 & 3.90 & 3.92 & 3.94 \\
\hline
\end{tabular}


Between group differences were not observed on the initial twenty attempts at the basket. However, in the second twenty attempts (trial two), Group B achieved a mean score $(M=27.25)$ significantly higher than Group A $(M=22.98)$. Group $C(M=25.43)$ did not differ statistically from $A$ or $B$.

In trial three, Group C $(M=30.18)$ scored significantly higher than Group B $(M=26.83)$, and Group $A(M=29.98)$ approached significance in scoring higher than Group B. Groups $A$ and $C$ did not differ statistically in their performances on this trial.

Group C, in trial four (attempts sixty-one to eighty), demonstrated superior performance, scoring significantly higher $(M=29.95)$ than Group $B(M=25.88)$ and slightly more effectively than Group $A$ $(M=27.15)$. Group $A$ did not differ statistically in performance from Groups B and C.

The end of practice test, attempts eighty-one to one-hundred, showed the effectiveness of a twenty-four hour rest interval between trials during practice. Group C performed greater than Groups $A$ and B at the .01 level of significance. Differences between Groups $A$ and $B$ were not significant, an indication that a five-minute rest was no more effective than no rest at all between trials. Group $C$ achieved a mean point score of 34.43 on this test, while Group B had 26.58 and Group A decreased to 25.18 .

Figure 1 summarizes pictorially the total findings of this study based on a 5-3-1 point scoring system. Since a substantial and statistically reliable difference was found between Group $C$ and Groups $A$ and $B$ on a test administered at the end of practice, it is evident that the immediate acquisition of a skill is to be favored over widely distributed practice periods rather than with continuous practice periods or with 


\section{F IGURE 1}

MASSED AND DISTRIBUTED PRACTICE EFFECTS ON THE ACQUISITION AND RETENTION OF A NOVEL BASKETBALL SKILL AS MEASURED BY THE MRAN NUMBER OF POINTS SCORED
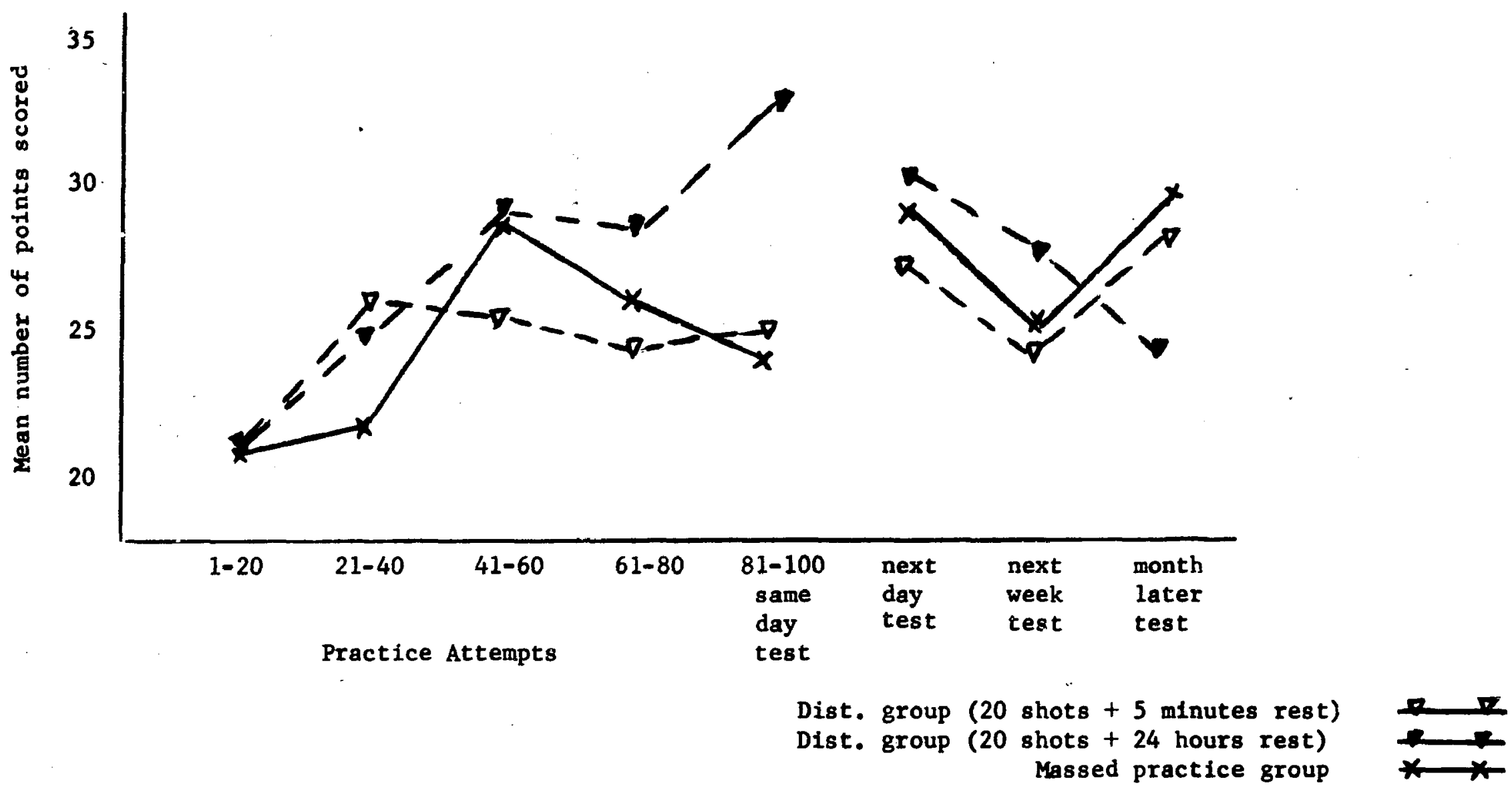
practice sessions separated by only five-minute rest intervals. Obviously, a five-minute rest period was not substantial enough to produce greater achievement results than no rest at all.

Because previous studies have sometimes demonstrated different criterion measures to produce conflicting results, it was decided to also analyze the data in terms of only the number of baskats made. Figure 2 presents the status of the learning groups at various intervals in the experiment in terms of baskets scored. A comparison of Figure 1 (page 64) and Figure 2 (page 66) reveals little difference between the two types of analysis as demonstrated by the relative scores of the groups.

Retention of the Skill

In order to test for retention and possible reminiscence, the groups were divided in half; tested one day later or one week following the completion of practice. All groups were tested one month aftex the conclusion of practice.

Table 5, page 67, contains the means and standard deviations of the group scores on the retention tests. Each retention test consisted of twenty attempts aic the basket.

An analysis of variance (Table 6, page 68) for the one day and one week later tests indicated a significant difference at the .05 level between test sessions. However, the significant F, 3.94, just barely attained significance over the tabled $F$ of 3.93 . 
MASSED AND DISTRIBUTED PRACTICE EFFECTS ON THE ACQUISITION AND RETENTION OF A NOVEL BASKETBALL SKILL AS MEASURED BY THE TOTAL BASKETS SCORED

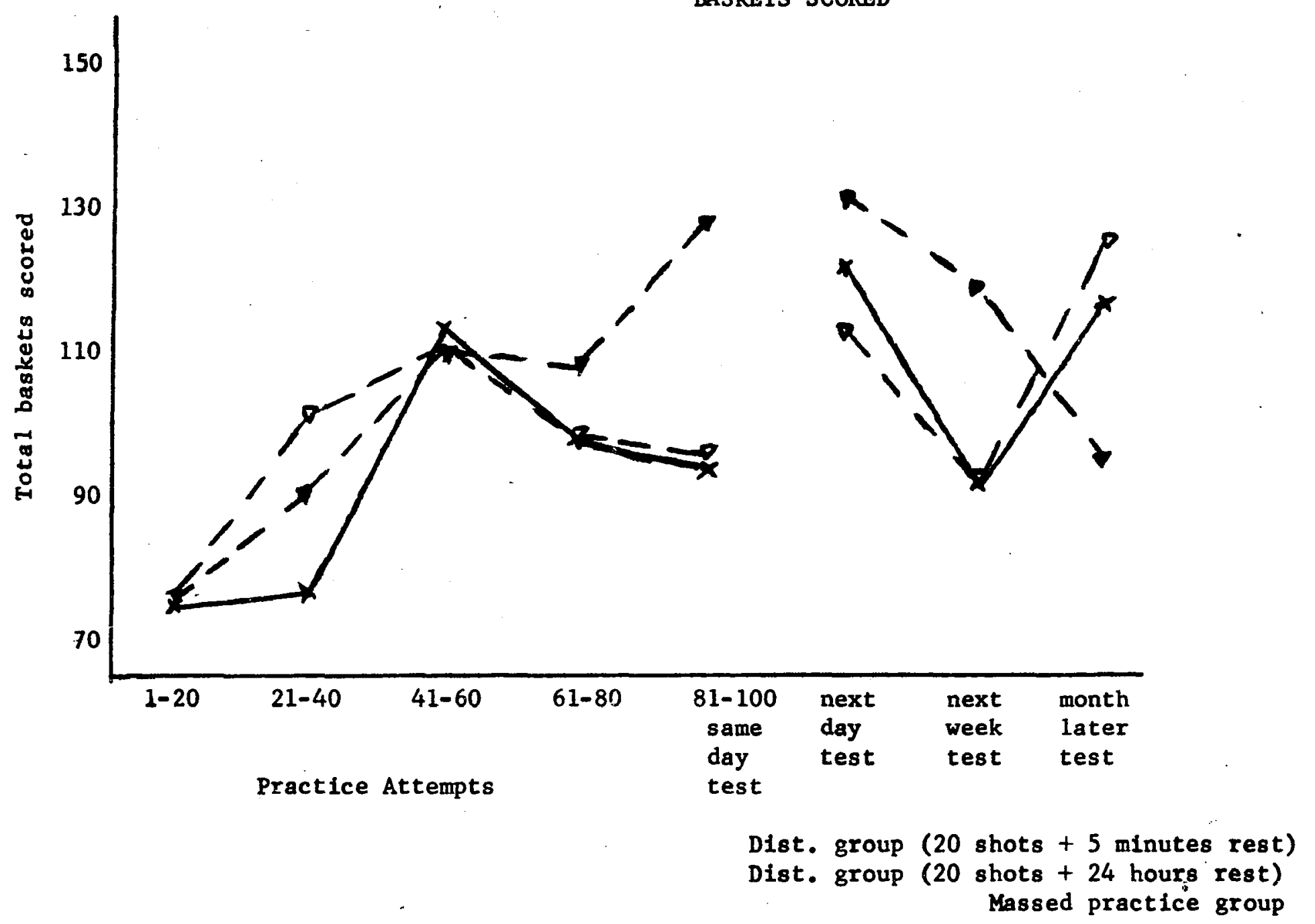


TABLE 5

MEAN SCORES AND STANDARD DEVIATIONS FOR MASSED AND DISTRIBUTED GROUPS TESTED FOR RETENTION

\begin{tabular}{cccccc}
\hline GROUPS** & & $\begin{array}{l}\text { same } \\
\text { day }\end{array}$ & $\begin{array}{l}\text { one } \\
\text { day } \\
\text { later }\end{array}$ & $\begin{array}{l}\text { TESTS* } \\
\text { one } \\
\text { week } \\
\text { later }\end{array}$ & $\begin{array}{l}\text { one } \\
\text { month } \\
\text { later }\end{array}$ \\
\hline A & M. & 25.18 & 31.10 & 26.65 & $\begin{array}{l}31.35 \\
11.3\end{array}$ \\
& S.D. & 9.5 & 9.7 & 11.4 & 11.3 \\
& M. & 26.58 & 29.10 & 25.60 & 30.25 \\
& S.D. & 12.1 & 8.1 & 8.7 & 12.8 \\
& M. & 34.43 & 32.30 & 29.65 & 25.48 \\
& S.D. & 10.4 & 8.8 & 11.3 & 10.6 \\
\hline
\end{tabular}

*20 trials each test.

**Group A: massed practice - had 80 continuous practice attempts. Group B: distributed practice - had 80 attempts with 5-minute rests after each 20 attempts. Group C: distributed practice - had 80 attempts with 24-hour rests after each 20 attempts. 
TABLE 6

ANALYSIS OF VARIANCE OF PERFORMANCE ON TESTS GIVEN ONE DAY AND ONE WEEK AFTER THE COMPLETION OF PRACTICE非

\begin{tabular}{lrrrr}
\hline \multicolumn{5}{c}{ Summary of Analysis of Variance } \\
\hline Source of variation & df & \multicolumn{1}{c}{ SS } & MS & F \\
\hline Test sessions & 1 & 374.6 & 374.6 & $3.94 *$ \\
Practice conditions & 2 & 265.1 & 132.6 & 1.39 \\
Tests X Conditions & 2 & 16.1 & 8.5 & .09 \\
Residual & 114 & 10841.6 & 95.1 & \\
Total & 119 & 11497.4 & & \\
\hline
\end{tabular}

*Significant at the .05 leve1. An $F$ based on 1 and 114 degrees of freedom must be 3.93 or larger to be significant at the .05 level.

非Sub-groups $(n=20) A_{1}, B_{1}$, and $C_{1}$ were tested one day later while $A_{2}, B_{2}$, and $C_{2}$ were tested one week after practice was terminated. 
Accordingly, the Duncan Range test used in Table 7, page 70, does not demonstrate any significant differences between means at the .05 leve1 of significance. It is a more conservative test for significance than most tests, relying on protection levels based on degrees of freedom which results in a gain in power in detecting real differences. 5 Table 8 , located on page 71 , contains the analysis of the scores attained at the conclusion of practice, at the first retention trial, the second retention trial, and the final retention trial, one month later. Following the three-factor experiment with repeated measures design as outlined by Winer, the plan in Table 8 may be classified as a $2 \times 3 \times 4$ factorial experiment, with repeated measures on the last factor. 6

The practice condition $\mathrm{X}$ test trial interaction is the only observed significant $F$, and the significance is at the .01 level. Hence, the data indicate that the shape of the retention curves are essentially different under the various practice conditions.

In Table 9, page 72, the means of the groups are presented and analyzed using the Duncan Multiple Range Test. Because the mean scores of the groups tested one day and one week after practice did not differ significantly, these scores were added together for each group and the new means classified as interpolated rest period means. Interpolated means of the groups were as follows: A - 28.88, B - 27.35, C -30.98 .

$$
\begin{aligned}
& 5_{\text {Duncan, }} \text { op. cit., pp. 1-42. } \\
& 6_{\text {Winer, }} \text { op. cit., pp. 337-344. }
\end{aligned}
$$


TABLE 7

DUNCAN MULTIPLE RANGE TEST ON ORDERED MEANS TO DETERMINE - SIGNIFICANCE OF THE DIFFERENCES BETWEEN MEANS OF GROUPS TESTED ONE DAY AND ONE WEEK FOLLOWING THE CONCLUSION OF PRACTICE

\begin{tabular}{|c|c|c|c|c|c|}
\hline \multicolumn{6}{|c|}{ Ordered Means } \\
\hline 1 & 2 & 3 & 4 & 5 & 6 \\
\hline 25.60 & 26.65 & 29.10 & 29.65 & 31.10 & 32.30 \\
\hline & 1.05 & $\begin{array}{l}3.50 \\
2.45\end{array}$ & $\begin{array}{r}4.05 \\
3.00 \\
.55\end{array}$ & $\begin{array}{l}5.50 \\
4.45 \\
2.00 \\
1.45\end{array}$ & $\begin{array}{l}6.70 \\
5.65 \\
3.20 \\
2.65 \\
1.20\end{array}$ \\
\hline
\end{tabular}

\begin{tabular}{|c|c|c|c|c|c|c|}
\hline $\begin{array}{l}\text { Rejection } \\
\text { value (.05 }\end{array}$ & 1eve1) & 2.77 & 2.92 & 3.02 & 3.09 & 3.15 \\
\hline$\left(\operatorname{Re} j_{0}\right)$ & $\left(S_{E}\right) *$ & 6.04 & 6.37 & 6.40 & 6.74 & 6.87 \\
\hline
\end{tabular}

$* S_{E}=2.18$ 
TABLE 8

ANALYSIS OF VARIANCE OF PERFORMANCE ON TESTS GIVEN AT THE END OF PRACTICE, AFTER INTERPOLATED REST PERIODS, AND ONE MONTH FOLLOWING THE COMPLETION OF PRACTICE

\begin{tabular}{|c|c|c|c|c|c|}
\hline \multicolumn{6}{|c|}{ Summary of Analysis of Variance } \\
\hline Source of variation & df & & SS & MS & $\mathbf{F}$ \\
\hline Between Subjects & 119 & & 25762.0 & & \\
\hline Interpolated groups (A) & 1 & & 462.4 & 462.4 & 2.14 \\
\hline Practice conditions (B) & 2 & • & 339.5 & 169.8 & 0.79 \\
\hline $\mathrm{A} \times \mathrm{B}$ & 2 & & 329 & 164.5 & 0.76 \\
\hline Subjects within groups & 114 & & 24631.1 & 216.1 & \\
\hline Within Subjects & 240 & & 17954.7 & & \\
\hline Test trials (C) & 2 & & 8.4 & 4.2 & 0.06 \\
\hline $\mathrm{AC}$ & 2 & & 97.5 & 48.8 & 0.75 \\
\hline $\mathrm{BC}$ & 4 & & 2694.5 & 673.6 & $10.28 * *$ \\
\hline$A B C$ & 4 & & 221.4 & 55.4 & 0.85 \\
\hline C X subjects w. groups & 228 & & 14932.9 & 65.5 & \\
\hline
\end{tabular}

**Significant at the .01 level. 
TABLE 9

DUNCAN MULTIPLE RANGE TEST ON ORDERED MEANS TO DETERMINE SIGNIFICANCE OF THE DIFFERENCES BETWEEN MEANS OF GROUPS TESTED AT THE END OF PRACTICE, AFTER INTERPOLATED REST PERIODS, AND ONE MONTH FOLLONING THE CONCLUSION OF PRACTICE

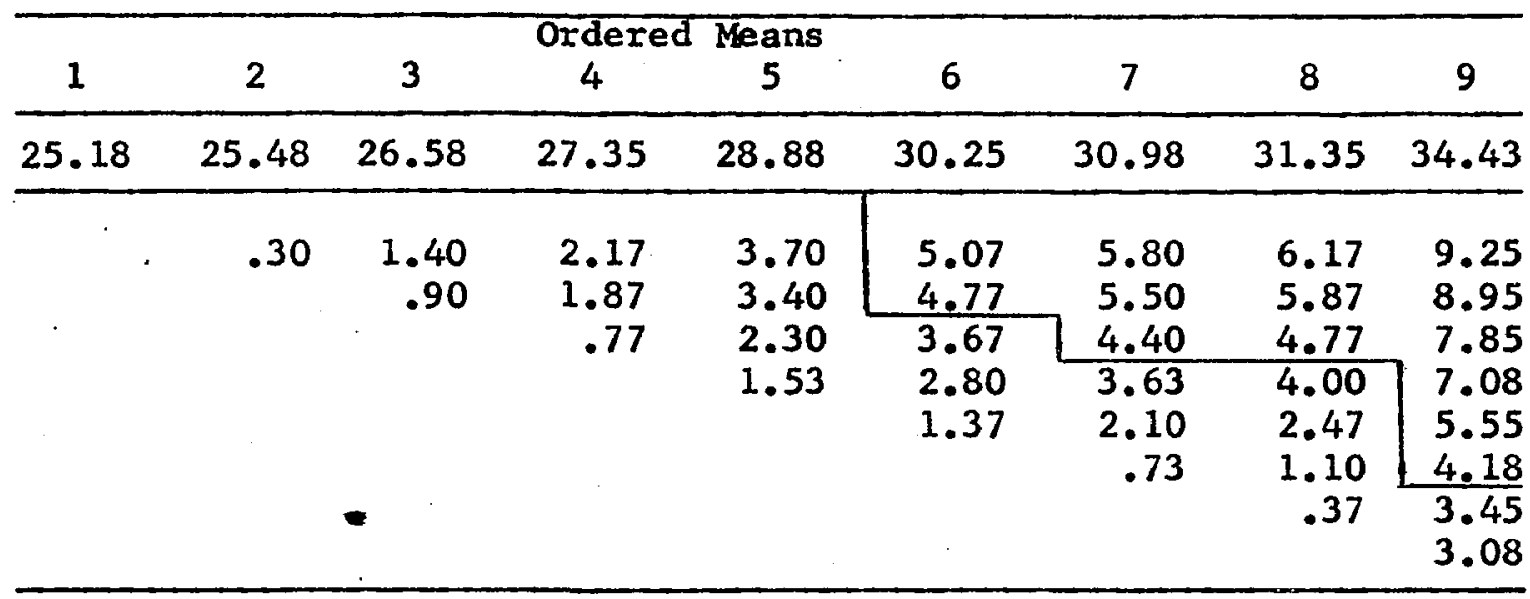

Rejection

value $\left(\begin{array}{llllllllll}(.05 & \text { level }) & 2.77 & 2.92 & 3.02 & 3.09 & 3.15 & 3.19 & 3.23 & 3.26 \\ \hline(\operatorname{Rej} .)\left(\mathrm{S}_{\mathrm{E}}\right) * & 3.55 & 3.74 & 3.87 & 3.96 & 4.03 & 4.08 & 4.13 & 4.17\end{array}\right.$

$* S_{E}=1.28$ 
Significant differences within each group may be noted in Table 9, page 72. Group A (massed) fell just short of performing significantly better during interpolated rest periods than immediately after practice. However, reminiscence, as reflected in a sudden improvement in performance not attributed to practice, was observed when Group A was tested after a twenty-four hour rest period following practice. Group A was significantly (.01 level) more effective one month later $(M=31.35)$ than immediately concluding practice $(M=25.48)$ demonstrating this improvement without any benefit of practice and therefore possibly due to the phenomena termed reminiscence.

Group B (five-minute rests) demonstrated increases in performance after the termination of practice which were not statistically significant at the .05 level. The mean score of the group was 26.58 at the end of practice, 27.35 after interpolated rests, and 30.25 one month after the conclusion of practice. Reminiscence effects were observed with Group B as wel1 as with Group A.

Group C (twenty-four hour ressts) decreased steadily on the retention tests.administered after practice. This group of subjects did significantly worse (.01 level) one month after the completion of practice $(M=25.48)$ than immediately following practice $(M=34.43)$. As was noted earlier, the test given directly after practice indicated that Group C did significantly better than Groups $A$ and B. No statistical differences were noted between the groups tested after interpolated rests. On the one month later retention test, Groups $A$ and B performed significantly higher than Group C. 
Since a substantial and statistically reliable rise was found after one month of no practice for Group $A$, it would seem that it is not feasible to argue that the locus of reminiscence is in the immediate vicinity of the learning process.

Also, learning and retention curves were extremely similar for the massed practiced group and the group which had five-minute rest pauses after each block of twenty attempts during practice. In turn, these curves were quite dissimilar from the curve obtained by the group which had rested twenty-four hours after every twenty attempts at the basket during practice. Evidently, in order for rest pauses to be meaningful in the learning of a gross motor skill, they must be of considerable duration.

As to the immediate acquisition of a gross motor skil1, this study appears to substantiate the findings of many other studies, i.e., greater rest intervals produce more efficient performance.

However, the retention findings of this study repudiate other experimental conclusions and theoretical explanations. It was expected that the intensity of interference or inhibition produced by massing or relatively massing, the practice would, to some extent, decrease with the passage of time. It is difficult to explain why Groups $A$ and $B$, after performing more effectively the day after practice, did poorer the next week and then so much better one month after a period of no practice. Why Groups A and B performed significantly superior to Group C one month after a period of no practice can also only be conjectured. There certainly does not seem to be any adequate or plausable explanation of these unusual findings. Although the one month later differences were statistically significant, possibly a chance factor was operating which 
altered the expected no-difference outcome on this retention test. Summary of analysis of data. The acquisition and retention of a novel basketball skill under three conditions of learning (massed, relatively massed, and distributed) was determined.

Acquisition of the skill was favored under twenty-four hour rest intervals between trials, with a five-minute pause only slightly more effective than continuous practice.

The massed practice group and the five-minute rest between trials group improved on interpolated rest tests, while the twenty-four hour rest between trials group performed worse. Differences were not significant between the groups. The final test of retention, presented one month after practice, demonstrated Group C to be significantly less efficient than Groups $A$ and $B$, with $A$ performing slightly superior to $B$. Reminiscence was observed with Groups A and B. 


\section{CHAPTER V}

SUMMARY AND CONCLUSIONS

\section{S UMMARY}

Educators have always been concerned with teaching methods whereby material might be learned and retained most effectively and efficiently. The problem of massing or distributing practlce as a means of obtaining desired results has been studied extensively by psychologists. It has received little attention from physical educators thus far.

This study was an attempt to discover the effects of massed and distributed practice on the acquisition and retention of a novel basketball skill, bouncing the ball off the floor and into the basket. The services of 120 male freshman students who were enrolled in this instructor's classes in the required physical education program during the spring and autumn quarters, 1963, were utilized for this study. The procedures employed in this study included (1) the selection of subjects, (2) instruction of the skill to be learned, (3) placement of the subjects into three groups, (4) eighty practice attempts for each subject, and (5) tests of twenty attempts administered at the completion of practice, one day following, one week later, and one month after the termination of practice.

Using a 5-3-1 point system, scores during and after practice were obtained and analyzed for each of the three groups: Group A practiced continuously until eighty attempts had been made at the basket, Group $B$ paused five minutes after each of four blocks of twenty shots, and Group C 
rested twenty-four hours following each of four blocks of twenty attempts at the basket.

Learning curves were found to be specific and related to the method of practice employed. An end of practice test indicated that the acquisition of the skill was favored with twenty-four hour rest intervals between trials, whereas massed practice and practice with five-minute rests between trials did not demonstrate any significant differences in the performances of the subjects.

Groups $A_{1}$ and $B_{1}$ performed more efficiently after a twenty-four hour rest (demonstrating reminiscence), while Group C did worse than at the termination of practice. All groups displayed a decrease in performance one week later, but Groups $A_{2}$ and $B_{2}$ were actually performing similarly to the end of practice. No significant differences were observed on these interpolated tests.

On a one month later test of retention, Groups $A$ and $B$ improved considerably (reminiscence observed) while Group C continued to score less efficiently. Groups A and B scored significantly higher than Group C, leading to the conclusion that massed or relatively massed practice is more profitable for long-term retention than is widely distributed practice.

\section{CONCLUSIONS}

From a theoretical point of view, the acquisition phase of this study could be handled adequately through Hullian explanatory terms. Added rest between trials permitted the dissipation of inhibitory factors. However, concerning retention, the data obtained from this present experiment does not contribute directly to the theory, as the theory holds that over a 
long time interval, reactive potential diminishes. Supposedly, reactive inhibition disappears after ten to twenty minutes of rest, resulting in increased performance at that time.

Some writers are of the opinion that perhaps $I_{R}$ lasts for a day or even a week. Even if it lasted for a month, there is no logical explanation why the disappearance of $I_{R}$ should result in a greater eventual performance for massed practice subjects than for distributed practice subjects. Considering that all subjects had experienced the same number of practice trials, the associated strength for the habit should at best be equal under massed and distributed conditions.

This study clearly brings out the importance of differentiating between learning and performance. Evidently test trials administered at the conclusion of practice will best indicate a performance level more or less dictated by the conditions of the practice; i.e., the relative spacing of the practice periods. The massing of trials depresses the level of performance, presumably because of the building up of inhibition. However, an intervening rest period permits the performance level to recover and this leads one to conclude that the massing of practice apparently exerts its effect on immediate performance rather than on learning itself.

As Griffith warns, practice does not always make perfect, especially if the practice is uninterrupted with rest intervals. Rest intervals definitely appear to favor immediate fine or gross motor skill performance but later retention is questionable in light of the results observed in the present study. ${ }^{1}$ Hubbard stresses the need to determine if psychology

${ }^{1}$ Coleman Griffith, Psychology and Athletics (New York: Charles Scribners Sons, 1928), pp. $195-196$. 
principles apply to sports' skills through increased emphasis on research in this area. 2 on the basis of the findings of this study related to immediate skill acquisition, psychological theory would be substantiated. Retention results would conflict with previous studies which found little difference between the effects of massed and distributed practice or possibly a slight favoring for distributed practice.

We can agree with Sharman when he states:

The available evidence indicates that physical education teachers should provide directed activity for relatively short periods throughout a semester rather than to practice each activity intensively for a short period and then leave it entirely while other activities are practiced intensively. 3

However, this confirmation of the previous statement can only be accepted if specified to apply to immediate skill acquisition and performance Not only does the area of retention have to be more thoroughly investigated, but also whether performers with different levels of skill will benefit more under one practice condition than another. In regards to this problem, Lawther expresses the feeling that beginners should practice often but not long in the early stages while the more advanced can profit from more concentrated practice over a longer duration. 4

It remains for investigators to further study such problems as these, related to learning conditions, especially as these conditions

2Alfred W. Hubbard, "Learning and Conditioning," College Physical Education Proceedings, 234-235, 1956.

${ }^{3}$ Jackson R. Sharman, The Teaching of Phys Ical Education (New York: A.S. Barnes and Company, 1936), pp. 132-133.

4John D. Lawther, "Methods and Principles in Motor Learning" (paper read at The Pennsylvania State University, University Park, Pennsylvania, 1961), p. 16. 
pertain to physical education. Physical educators should be concerned with skill acquisition and more important, the retention of that which has been learned. The wide acceptability of distributing practice for immediate skill performance has been upheld by the results of this study. The retention results, although statistically favoring massed and relatively massed practice over distributed practice, can only be presented with reservation in the hope that further investigation in this area will pave the way for a greater understanding of the learning process. 


\section{BIBLIOGRAPHY}

Books

Bucher, Charles. Foundations of Physical Education. St. Louis: The C.V. Mosby Company, 1960 .

Deese, James. The Psychology of Learning. New York: McGraw-Hill Book Company, Inc., 1958.

Gagne, Robert M., and Fleishman, Edwin A. Psychology of Human Performance. New York: Henry Holt and Company, 1959.

Griffith, Coleman. Psychology and Athletics. New York: Charles Scribners Sons, 1928. Sons, 1932 .

Hilgard, Ernest k. Theories of Learning. New York: Appleton-CenturyCrofts, Inc., 1956.

Hu11, Clark L. Principles of Behavior. New York: D. Appleton-Century Company, 1943.

McGeoch, John A., and Irion, Arthur L. The Psychology of Human Learning. New York: Van Rees Press, 1952.

Rarick, G. Lawrence. "Physical Education," Encyclopedia of Educational Research, Chester W. Harris, Ed. New York: The Macmillan Company, 1960, p. 984.

Sharman, Jackson R. The Teaching of Physical Education. New York: A.S. Barnes and Company, 1936.

Winer, B.J. Statistical Principles in Experimental Design. New York: McGraw-Hill Book Company, Inc., 1962.

\section{Periodicals}

Ammons, Robert B. "Acquisition of Motor Skill: II. Rotary Pursuit Performance with Continuous Practice Before and After a Single Rest," Journal of Experimental Psychology, 37:393-411, October, 1947. 
Ammons, Robert B. "Effect of Distribution of Practice on Rotary Pursuit "Hits"," Journal of Experimental Psychology, 41:17-22, January, 1951.

- "Acquisition of Motor Skill: III. Effects of Initially Distributed Practice on Rotary Pursuit Performance," Journal of Experimental Psychology, 40:778-787, December, 1950.

Archer, E. James. "Postrest Performance in Motor Learning as a Function of Prerest Degree of Distribution of Practice;" Journal of Experimental Psychology, 47:47-51, January, 1954.

Austin, Sarah D. "A Study in Logical Memory," The American Journal of Psychology, 32:370-403, July, 1921.

Ballard, Philip B. "Oblivisence and Reminiscence," British Journal of Psychology Monograph Supplements, No. 2, 1913 .

Batson, William H. "Acquisition of Skill," Psychological Monograph, 21:1-94, July, 1916.

Be11, Hugh M. "Rest Pauses in Motor Learning as Related to Snoddy's Hypothesis of Mental Growth," Psychological Monographs, 54:1-38, 1942.

Bilodeau, Edward A. "Performance Decrement In a Simple Motor Task Before and After a Single Rest," Journal of Experimental Psychology, 43:381-390, May, 1952 .

Bunch, M.E. "The Measurement of Reminiscence," The Psychological Review, 45:523-531, November, 1938.

Burton, Claude E. "Reminiscence in the Acquisition of Ski11," Psychological Review, 49:191-196, March, 1942.

"The Status of Research in Reminiscence," Psychological Bulletin, 40:313-340, May, 1943.

Cain, Leo F., and Willey, Roy DeVer1. "The Effect of Spaced Learning on the Curve of Retention," Journal of Experimental Psychology,

25:209-214, August, 1939.

Carr, Harvey, "Distribution of Effort," Psychological Bullerin, 16:26-28, January, 1919.

Cook, Barbara S., and Hilgard, Ernest R. "Distributed Practice in Motor Learning: Progressively Increasing and Decreasing Rests," Journal of Experimental Psychology, 39:169-172, April, 1949.

Cook, Sidney A. "The Effects of Various Temporal Arrangements of Practice on the Mastery of an Animal Maze of Moderate Complexity," Archives of Psychology, No: 98, April, 1928. 
Cook, Thomas W. "Massed and Distributed Practice in Puzzle Solving," The Psychological Review, 41:330-355, July, 1934.

- "Distribution of Practice and Size of Maze Pattern," British Journal of Psychology, 27:303-312, January, 1937.

- "Factors in Massed and Distributed Practice," Journal of Experimental Psychology, 34:325-334, September, 1944.

Crawford, Meredith P., et al., Ed. "Psychological Research on Operational Training in the Continental Air Forces," Army Air Forces Aviation Psychology Program Research Reports, 16:260-262, 1947.

Cummins, Robert A. "Improvement and the Distribution of Practice," Teachers College Contributions to Education, No. 97, 1919.

Dore, Leon R., and Hilgard, Ernest R. "Spaced Practice and the Maturation Hypothesis," Journal of Psychology, 4:245-259, 1937.

- "Spaced Practice as a Test of Snoddy's Two Processes in Mental Growth," Journal of Experimental Psychology, 23:359-374, October, 1938.

Duncan, David B. "Multiple Range and Multiple F Tests," Biometrics, 2:1-42, March, 1955.

Duncan, Carl P. "The Effect of Unequal Amounts of Practice on Motor Learning Before and After Rest," Journal of Experimental Psychology, 42:257-264, October, 1951 .

E1lis, Douglas S. "Distribution Theory and the Effort Variables,"

- Psychological Review, 60:383-392, November, 1953.

Ellis, Douglas S., Montgomery, Victor, and Underwood, Bent on $\mathrm{J}$. "Reminiscence in a Manipulative Task as a Function of Work-Surface Height, Prerest Practice, and Interpolated Rest," Journal of Experimental Psychology, 44:420-427, December, 1952 .

- Eriksen, Stanford C. "Variability of Attack in Massed and Distributed Practice," Journal of Experimental Psychology, 31:339-345, November, $19 \overline{42 .}$

Fox, Margaret G., and Lamb, Ethel. "Improvement During a Non-practice Period in a Selected Physical Education Activity," The Research Quarterly, 33:381-385, October, 1962.

Fox, Margaret G., and Young, Vera P. "Effect of Reminiscence on Learning Selected Badminton Skills," The Research Quarterly, 33:386-394, October, 1962. 
Franklin, Joseph C., and Brozek, Josef. "The Relation Between Distribution of Practice and Learning Bfficiency in Psychomotor Performance, Journal of Experimental Psychology, 39:16-24, February, 1947 .

Garrett, Henry E. "Variability in Learning Under Massed and Spaced Practice," Journal of Experimental Psychology, 26:547-567, June, 1940.

Gentry, John R. "Immediate Effects of Interpolated Rest Periods on Leaming Performance," Teachers College Contributions to Education, No. $799,1940$.

Hardy, Mattie C. "The Effect of Distribution of Practice in Learning a Stylus Maze," The Journal of Comparative Psychology, 10:85-96, February, 1930.

Gordon, Kate. "Class Results with Spaced and Unspaced Memorizing," Journal of Experimental Psychology, 8:337-343, October, 1925.

Harmon, John $\mathrm{M}_{0}$, and Miller, Arthur G. "Time Patterns in Motor Learning," The Research Quarterly, 21:182-187, October, 1950 .

Hilgard; Ernest $R_{0}$, and Smith Mo Brewster. "Distributed Practice in Motor Learning: Score Changes Within and Between Daily Sessions," Journal of Experimental Psychology, 30:136-146, February, 1942.

Hovland, Carl. "Experimental studies in Rote-Learning Theory. I. Reminiscence Following Learning by Massed and Distributed Practice," Journal of Experimental Psychology, 22:201-224, March, 1938.

- "Experimental Studies in Rote-Learning Theory. III. Distribution of Practice With Varying Speeds of Syllable Presentation," Journal of Experimental Psychology, 23:172-190, August, 1938.

- "Experimental Studies in Rote-Learning Theory. VI. Comparison of Retention following Learning to Same Criterion by Massed and Distributed Practice, Journal of Experimental Psychology, 26:568-589, June, 1940 .

Hovland, Car1., and Kurtz, Kenneth H. "Experimental Studies in RoteLearning Theory: IX. Influence of Work-Decrement Factors on Verbal Learning," Journal of Experimental Psychology, 42:265-272, October, 1951.

Hubbard, Alfred W. "Learning and Conditioning," College Physical Education Proceedings, 234-235, 1956.

Irion, Arthur L. "Reminiscence in Pursuit-Rotor Learning As A Function of Length of Rest and of Amount of Pre-Rest Practice," Journal of Experimental Psychology, 39:492-499, August, 1949. 
Jahnke, John C. "Postrest Motor Learning Performance as a Function of Degree of Learning," Journal of Experimental Psychology; 62:605-611, December, 1961.

Jahnke, John C., and Duncan, Car1 P. "Reminiscence and Forgetting in Motor Learning After Extended Rest Intervals," Journal of Experimental Psychology, 52:273-282, November, 1956.

Kientzle, Mary J. "Properties of Learning Curves Under Varied Distributions of Practice," Journal of Experimental Psychology, 36:187-211, June, 1946.

- "Ability Patterns Under Distributed Practice," Journal of Experimental Psychology, 39:532-537, August, 1949.

Kimble, Gregory A. "An Experimental Test of a Two-Factor Theory of Inhibition," Journal of Experimental Psychology, 29:15-23, February, 1949.

- "Performance and Reminiscence in Motor Learning as a Function of the Degree of Distribution of Practice," Journal of Experimental Psychology, 39:591-510, August, 1949.

Kimble, Gregory A., and Horenstein, Betty R. "Reminiscence in Motor Learning as a Function of Length of Interpolated Rest," Journal of Experimental Psychology, 38:239-244, June, 1948.

Knapp, Clyde G., and Dixon, W. Robert. "Learning to Juggle:. I. A Study to Determine the Effect of Two Different Distributions of Practice on Learning Efficiency," The Research Quarterly, 21:331-336, October, 1950.

Lashley, K.S. "The Acquisition of Skill in Archery," Papers From The Department of Marine Biology of the Carnegie Institute of Washington, $7: 105-128,1915$.

Leuba, James $\mathrm{H}_{0}$, and Hyde, Winifred. "An Experiment in Learning to Make Hand Movements," The Psychological Review, 12:351-369, November, 1905.

Lewis, Don, and Lowe, William F. "Retention of Sk111 on the SAM Complex Coordinator," " Proceedings of the Iowa Academy of Science, $63: 591-599,1956$.

Lorge, Irving. "Influence of Regularly Interpolated Time Intervals Upon Subsequent Learning," Teachers College Contributions to Education, No. 438,1930 .

Lyon, Darwin 0. "The Relation of Length of Material to Time Taken For Learning and the Optimum Distribution of Time," Journal of Educational Psychology, 5:85-91, 1914 . 
Massey, Dorothy. "The Significance of Interpolated Time Intervals on Motor Learning," The Research Quarterly, 30:189-201, May, 1959.

McClelland, David C. "Studies in Serial Verbal Discrimination Learning. I. Reminiscence with Two Speeds of Pair Presentation," Journal of Experimental Psychology, 31:44-56, July, 1942.

McGeoch, Grace O. "The Conditions of Reminiscence," The American Journal of Psychology, 47:65-87, January, 1935 .

Nohr, Dorothy R. "The Contributions of Physical Activity to Skill Learning, The Research Quarter1y, 31:321-351, May, 1960, Part II.

Montgomery, Victor E. "Transfer of Training in Motor Learning as a Function of Distribution of Practice," Journal of Experimental Psychology, 46:440-445, December, 1953.

Murphy, Herbert H. "Distribution of Practice Periods in Learning," The Journal of Educational Psychology, 7:150-162, January, 1916.

Newman, Edwin B. "Effect of Crowding of Material on Curves of Forgetting," The American Journal of Psychology, 52:601-609, October, 1939.

Noble, Clyde E. "Absence of Reminiscence in the Serial Rote Learning of Adjectives," Journal of Experimental Psychology, 40:622-631, Oatober, 1950

Oseas, Leonard, and Underwood, Benton J. "Studies of Distributed Practice: V. Learning and Retention of Concepts," Journal of Experimental Psychology, 43:143-148, February, 1952.

Patten, Everett F. "The Influence of Distribution of Repetitions on Certain Rote Learning Phenomena," Journal of Psychology, 5:359-374, 1938.

Pechstein, L.A. "Massed Versus Distributed Effort in Learning," The Journal of Educational Psychology, 12:92-97, February, $19 \overline{21 .}$

Perkins, Nellie L. "The Value of Distributed Repetitions in Rote Learning," British Journal of Psychology, 7:253-261, September, 1914 .

Purdy, Bonnie J., and Lockhart, Aileene. "Retention and Relearning of Gross Motor Skills After Long Periods of No Practice," The Research Quarterly, 33:265-272, May, 1962.

Pyle, W.H. "Economical Learning," The Journal of Educational Psychology, 4:148-158, January, 1913.

- "Concentrated Versus Distributed Practice,". The Joumal of Educational Psychology, 5:247-259, May, 1914. 
Reynolds, Bradley, and Bilodeau, Ina McD. "Acquisition and Retention of 3 Psychomotor Tests as a Function of Distribution of Practice During Acquisition," Journal of Experimental Psychology, 44:19-26, July, 1952.

Riope1le, Arthur J. "Psychomotor Performance and Distribution of Practice," Journal of Experimental Psychology, 40:390-393, June, 1950.

Robinson, Edward s. "The Relative Efficiencies of Distributed and Concentrated Study in Memorizing," Journal of Experimental Psychology, 4:327-343, October, $19 \overline{21 .}$

Rubin-Rabson, Grace. "Studies in the Psychology of Memorizing of Piano Music: II. A Comparison of Massed and Distributed Practice," Journal of Educational Psychology, 31:270-284, April, 1940.

Snoddy, George S. "Learning and Stability," The Journal of Applied Psychology, 10:1-36, 1926.

Swift, Edgar J. "Memory of a Complex Skillful Act," The American Journal of Psychology, 16:131-133, January, 1905.

- "Memory of Skillful Movements," The Psychology Bullet in, 3:185-187, June 15, 1906.

- "Relearning a Skillful Act: An Experimental Study in Neuro-Muscular Memory," The Psychology Bulletin, 7:17-19, January 15, 1910.

Travis, Roland C. "Length of the Practice Period and Efficiency in Motor Learning," Journal of Experimental Psychology, 24:339-345, March, 1939.

Tsao, J.C. "Shifting of Distribution of Practice in Mirror Drawing," Journal of Experimental Psychology, 40:639-642, October, 1950.

Underwood, Benton J. "Studies of Distributed Practice: XV. Verbal Concept Learning as a Function of Intralist Interference," Journal of Experimental Psychology, 54:33-40, July, 1957.

- "Studies of Distributed Practice: XVI. Some Evidence on the Nature of the Inhibition Involved in Massed Learning of Verbal Materials," Journal of Experimental Psychology, 54:139-143, August, 1957.

Ward, Lewis B. "Reminiscence and Rote Learning," Psychological Monographs, 49: 1-64, 1937.

Williams, Osborne. "A Study of the Phenomenon of Reminiscence," Journal of Experimental Psychology, 9:368-387, October, 1926. 
Wright, Susan T.H., and Taylor, Donald W. "Distributed Practice in Verbal Learning and the Maturation Hypothesis," Journal of Experimental Psychology, 39:527-531, August, $19 \overline{49}$ •

Young, Olive G. "Rate of Learning in Relation to Spacing of Practice Periods in Archery and Badminton," The Research Quarterly, 25:231-243, May, 1954.

\section{Unpublished Materials}

Black, Joanne. "An Experimental Study of the Learning of Motor Skill" (unpublished Master's thesis, The Pennsylvania State University, 1949).

Lawther, John D. "Methods and Principles in Motor Learning" (paper read at The Pennsylvania State University, University Park, Pennsylvania, 1961). 